\title{
1 AMOC and summer sea ice as key drivers of the spread in Mid-Holocene winter 2 temperature patterns over Europe in PMIP3 models
}

4 Alina Găinuşă-Bogdan ${ }^{1,2}$, Didier Swingedouw ${ }^{1}$, Pascal Yiou ${ }^{2}$, Julien Cattiaux ${ }^{3}$, Francis 5 Codron $^{4}$ and Simon Michel ${ }^{1}$

$6 \quad{ }^{1}$ Environnements et Paléoenvironnements Océaniques et Continentaux (EPOC), UMR CNRS 75805 EPOC-OASU-Université de Bordeaux, Allée Geoffroy Saint-Hilaire, Pessac 33615, 8 France.

$9{ }^{2}$ Laboratoire des Sciences du Climat et de l'Environnement, UMR8212 CEA-CNRS-UVSQ, 10 Institut Pierre Simon Laplace, Université Paris-Saclay, 91191 Gif-sur-Yvette, France

$11{ }^{3}$ Centre National de Recherches Météorologiques, Université de Toulouse, UMR 3589 12 CNRS/Météo-France, Toulouse, France.

$13{ }^{4}$ Sorbonne Université, CNRS, IRD, MNHN, Laboratoire d'Océanographie et du Climat 14 (LOCEAN/IPSL), 4 place Jussieu, Paris F-75005, France.

16 Contact: alina.gainusabogdan@gmail.com

\section{Abstract}

The mid-Holocene $(6,000$ years before present) was a warmer period than today in summer in most of the Northern Hemisphere. In winter, over Europe, pollen-based reconstructions show a dipole of temperature anomalies as compared to present-day, with warmer conditions in the north and colder in the south. It has been proposed that this pattern of temperature anomaly could be explained by a persisting positive phase of the North Atlantic Oscillation during this period, which was, however, not reproduced in general by climate models. Indeed, PMIP3 models show a large spread in their response to the mid-Holocene insolation changes, the 25 physical origins of which are not understood. To improve the understanding of the 
reconstructed temperature changes and of the PMIP3 model spread, we analyze the dynamical response of these model simulations in the North Atlantic for mid-Holocene conditions as compared to pre-industrial. We focus on the European pattern of temperature in winter and compare the simulations with a pollen-based reconstruction. We find that some of the model simulations yield a similar pattern to the reconstructed one, but with far lower amplitude, although it remains within the reconstruction uncertainty. We attribute the northern warm part of the latitudinal dipole of temperature anomaly in winter to a lower sea-ice cover in the Nordic Seas. The decrease of sea ice in winter indeed reduces the local sea-ice insulation effect, allowing the released ocean heat to reach continental northern Europe. This decrease in winter sea-ice cover is related to an increase in the Atlantic meridional overturning circulation (AMOC) and its associated ocean heat transport, as well as the effect of insolation changes on sea ice in summer, which persists until winter. We only find a slight cooling signal over southern Europe, compared to reconstructions, mainly related to the insolation-induced cooling in winter over Africa. We show that the models that failed to reproduce any AMOC increase under mid-Holocene conditions are also the ones that do not reproduce the temperature pattern over Europe. The change in sea level pressure is not sufficient to explain the spread among the models. The ocean-sea ice mechanisms that we proposed constitute an alternative explanation to the pattern of changes in winter temperatures over Europe in the mid-Holocene, which is in better agreement with available model simulations of this period. Finally, we evaluate if reconstructions of the AMOC for the mid-Holocene can provide interesting emerging constraints on key changes in European climate, and indirectly on AMOC response to on-going and future radiative changes. Although there is a significant link between the response of the mid-Holocene and projections, it remains limited. The proposed mechanism does not appear to be sufficient to explain the large discrepancies between models and reconstruction data for the summertime period. 


\section{Introduction}

53 Projections of the climate of Europe show a large spread for the ongoing century (IPCC

54 Working Group 1 et al. 2013). For a given emission scenario, uncertainties are related to the internal variability, that can be large at the regional scale (Deser et al. 2012), and to the model-dependent sensitivity of the climate system to external forcings (Hawkins and Sutton 2009). In particular, changes of the atmospheric or oceanic circulation tend to vary a lot between models. Future projections of the North Atlantic Oscillation (NAO), that plays a crucial role in the climate variability of Europe in winter (Hurrell 1995), do not even agree on its sign (Cattiaux and Cassou 2013). At multi-decadal timescales, the Atlantic Meridional Overturning Circulation (AMOC) also plays a key role for the climate of Europe through its massive northward transport of heat all along the Atlantic Ocean (Swingedouw et al. 2009, Haarsma et al. 2015, Jackson et al. 2015). Its long-term projections are, similarly, very uncertain (Weaver et al. 2012), even though all the models agree that it should decrease in the coming century, especially when the Greenland ice sheet melting is accounted for (Bakker et al. 2016; Swingedouw et al. 2015a). To improve our estimate of the response of the NAO or the AMOC to external forcing, paleoclimate data could provide key observational constraints (Schmidt et al. 2014; Harrison et al. 2015).

Paleoclimate reconstructions are based on proxy records that have been collected for decades around the world. The main issue with proxies is that they are indirect records of climate variables, so that they could be subject to large uncertainties and biases. Nevertheless, except for the short instrumental era, they are the only observational estimates of the climate response to different external forcings. Even though there is no exact analogue of the future in the past, information on the climate response to changes in external forcings has a high relevance to better evaluate the sensitivity of climate models and possibly reduce the 

regional scale.

86 uncertainty concerning the on-going climate change (Schmidt et al. 2014), especially at the

The mid-Holocene (MH: 6000 years Before Present) is a period for which reconstructions suggest a mean climate of the northern high latitudes that was considerably warmer than today in summer (Fischer et al. 2018), due to a different insolation forcing (Figure 1). This is an interesting climate period, when the Sahara is suspected to have been greener than today (Claussen and Gayler 1997). This is why the Paleoclimate Model Intercomparison Project, phase 3 (PMIP3) initiative (Braconnot et al. 2012) proposed this period as a key snapshot to be simulated by the same climate models that produce climate projections (Schmidt et al. 2014; Harrison et al. 2015).

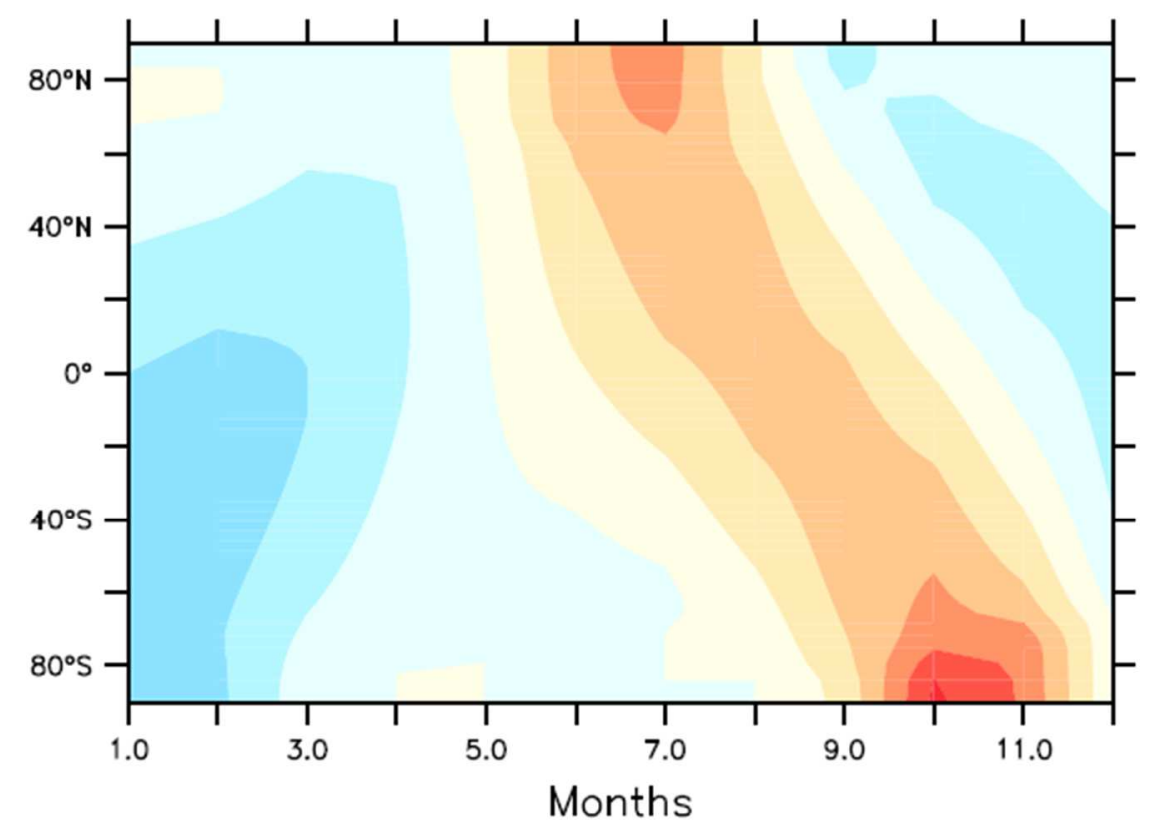

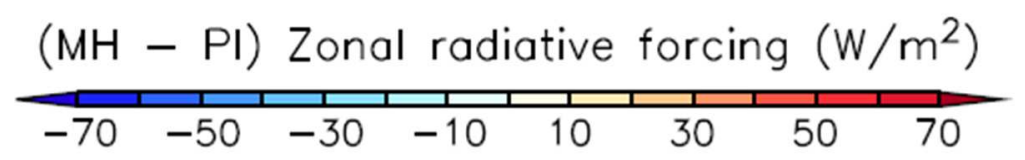

Figure 1: Zonally-averaged climatological monthly differences in the incoming shortwave radiation at the top of the atmosphere between mid-Holocene and pre-industrial simulations. 
A recent study proposed an improved reconstruction of climate over Europe for the MH based on a broad compilation of pollen data (Mauri et al. 2014). The results showed a dipole of winter near-surface temperature anomalies, with warm anomalies in the north of Europe and cold anomalies in the south. The authors suggested this pattern could be caused by an atmospheric circulation anomaly similar to a positive phase of the North Atlantic Oscillation $\left(\mathrm{NAO}^{+}\right)$. Other studies also proposed such a change for mid-Holocene European climate in winter (Guyard et al. 2013; Chabaud et al. 2014). This hypothesis therefore provides an interesting testbed for climate models. Mauri et al. (2014) argued that PMIP3 simulations in general did not reproduce very well the reconstructed dipole in temperature in winter because they do not show any $\mathrm{NAO}^{+}$-like changes in atmospheric circulation for the MH. This was also the case for the older PMIP2 dataset (Gladstone et al. 2005). Nevertheless, it has been proposed that PMIP2 dataset still showed some skill in capturing the pattern of climate change over Europe for the MH (Brewer et al. 2007). While the new generation of PMIP3 models show larger changes in sea ice for MH conditions than PMIP2 models over the Arctic (Berger et al. 2013), which may impact the response over Europe, a quantitative comparison of the PMIP3 models with winter reconstruction of temperature over Europe has not been made yet. Furthermore, a detailed analysis of the mechanism explaining the wintertime response in PMIP3 simulations for $\mathrm{MH}$ is also missing for the North Atlantic.

The large increase in summer insolation for $\mathrm{MH}$ conditions may have strongly affected the sea ice in polar regions, even in winter through inertia. This could then influence the continental climate, notably in winter where the heat flux release by the ocean is largest, as well as the insulation effect of sea ice (Goosse et al. 2002). Such an impact was illustrated by Fischer and Jungclaus (2011) in a transient simulation over part of the Holocene using the MPI climate model. Otto et al. (2009), using different simulations for the MH where the coupling between the ocean and vegetation was either activated or not, also showed that the ocean plays a key role for the amplitude of the temperature response of the northern high 
116 latitudes to the radiative forcing. The insolation during the MH was indeed very different

117 from the pre-industrial period. The latitudinal gradient was strongly reduced during the

118 summer season, which could have impacted the oceanic and atmospheric meridional heat

119 transport (Davis and Brewer 2009).

120 In the present study, we propose to analyze the response of climate models participating in

121 PMIP3 under MH wintertime conditions, with a specific focus on the North Atlantic region.

122 We will assess the potential causes for the model spread in temperature response over Europe 123 in winter and analyze the role played by changes in atmospheric circulation, oceanic 124 circulation and radiative changes amplified by sea ice response. We will also compare these 125 simulations, using classical skill scores, with the reconstruction of Mauri et al. (2014). This 126 will allow us to determine the models that best reproduce the temperature dipole pattern over

127 Europe. Our main result is that atmospheric circulation changes are not the main driver of the 128 simulated patterns of temperature anomalies. These are instead linked to sea-ice anomalies, 129 forced either by AMOC slowdown or summer sea-ice melt.

130 Experimental design

131 We analyze pairs of mid-Holocene and pre-industrial (PI) simulations performed with PMIP3

132 climate models. Only 12 models (Table 1) are retained, as we require at least 100 years of 133 both PI and MH simulations to perform robust statistical analyses. When more than 200 134 model years are available, we use the last 200 years of the simulation. Throughout the 135 analyses, we use data on the native grid for each model, except when multi-model statistics 136 are calculated, in which case the model data is first interpolated on a regular $1^{\circ} \times 1^{\circ}$ grid for the 137 temperature to be compared with Mauri et al. (2014) and a regular $2.5^{\circ} \times 2.5^{\circ}$ grid for the other 138 variables. We also use RCP85 projections of the AMOC for the CMIP5 models available in 
139 order to compare the simulated changes in the AMOC in these projections to those for the 140 mid-Holocene.

Index Model Modeling Center Reference

\begin{tabular}{|c|c|c|c|}
\hline A & bcc-csm1-1 & Beijing Climate Center (BCC) & Xin et al. (2013) \\
\hline B & CNRM-CM5 & $\begin{array}{l}\text { Centre National de Recherches Météorologiques/ } \\
\text { Centre Européen de Recherche et Formation } \\
\text { Avancées en Calcul Scientifique } \\
\text { (CNRM/CERFACS) }\end{array}$ & Voldoire et al. (2013) \\
\hline $\mathrm{C}$ & CSIRO-Mk3-6-0 & $\begin{array}{l}\text { Commonwealth Scientific and Industrial } \\
\text { Research Organization/ Queensland Climate } \\
\text { Change Centre of Excellence (CSIRO-QCCCE) }\end{array}$ & Rotstayn et al. (2012) \\
\hline $\mathrm{D}$ & IPSL-CM5A-LR & Institut Pierre-Simon Laplace (IPSL) & $\begin{array}{l}\text { Dufresne et al. } \\
\text { (Dufresne et al. 2013) }\end{array}$ \\
\hline $\mathrm{E}$ & FGOALS-g2 & $\begin{array}{l}\text { State Key Laboratory of Numerical Modeling for } \\
\text { Atmospheric Sciences and Geophysical Fluid } \\
\text { Dynamics/Institute of Atmospheric Physics } \\
\text { (LASG/IAP) }\end{array}$ & Li et al. (2013) \\
\hline $\mathrm{F}$ & FGOALS-s2 & LASG/IAP & Bao et al. (2013) \\
\hline G & MIROC-ESM & $\begin{array}{l}\text { Atmosphere and Ocean Research Institute } \\
\text { (The University of Tokyo), National Institute for } \\
\text { Environmental Studies, and Japan Agency for } \\
\text { Marine-Earth Science and Technology }\end{array}$ & Watanabe et al. (2011) \\
\hline $\mathrm{H}$ & HadGEM2-ES & Met Office Hadley Center (MOHC) & Collins et al. (2011) \\
\hline I & MPI-ESM & Max Planck Institute for Meteorology (MPI-M) & Jungclaus et al. (2013) \\
\hline $\mathrm{J}$ & MRI-CGCM3 & Meteorological Research Institute (MRI) & Yukimoto et al. (2012) \\
\hline K & GISS-E2-R & NASA Goddard Institute for Space Studies & Schmidt et al. (2006) \\
\hline $\mathrm{L}$ & CCSM4 & $\begin{array}{l}\text { National Center for Atmospheric } \\
\text { Research (NCAR) }\end{array}$ & Gent et al. (2011) \\
\hline
\end{tabular}

141

142

144 industrial period for wintertime (December-February averages - DJF), summertime (June-

145 August averages - JJA) or annual means (ANM). Wherever suitable, we use a two-sided

146 independent sample t-test to determine if and to what level these anomalies are statistically

147 significant, considering the interannual variability in the PI and MH simulations, at each grid 
148 point. Where this is done, we shade in color the regions where the anomalies are significant at

149 the $90 \%$ confidence level. For a more stringent test, we add contours corresponding to

150 significant anomalies at the $99 \%$ confidence interval.

\section{Temperature and circulation response}

\section{MH winter temperature response in PMIP3 models}

153 While the external forcing (insolation changes) is the same in the different models, their

154 responses to $\mathrm{MH}$ climatic condition in winter over Europe are very different, as illustrated in

155 Figure 2. This figure shows the significant winter surface atmospheric temperature (SAT)

156 anomalies over Europe simulated with the 12 different climate models, the multi-model

157 ensemble mean anomaly and the reconstruction by Mauri et al. (2014). The uncertainties in

158 the pollen-based reconstruction can be quite large, therefore Figure $2 \mathrm{n}$ only shows those

$159 \Delta \mathrm{SAT}_{\mathrm{DJF}, \mathrm{EU}}$ values that are larger in absolute value than the respective estimated uncertainties.

160 We find a wide range of simulated SAT anomaly patterns between the 12 models, and some

161 important differences from the mean reconstructed pattern. We quantify these model-

162 reconstruction differences in Figure 3, showing the pattern correlation, pattern root-mean-

163 square difference (RMSE; pattern RMSE obtained by removing the respective spatial average

164 from each field before the RMSE calculation) and full-field RMSE for each model compared

165 to the Mauri et al. (2014) reconstruction, as well as for the multi-model ensemble mean. 
(a) bcc-csm 1-1

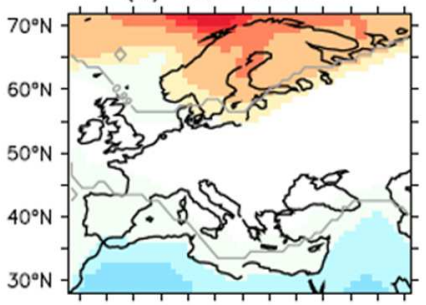

(e) FGOALS - g2

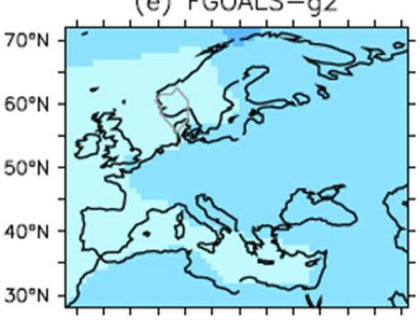

(i) MPI-ESM-P

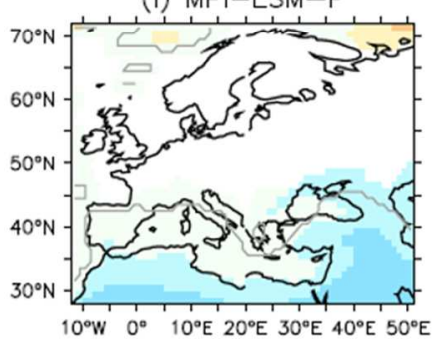

(b) CNRM-CM5

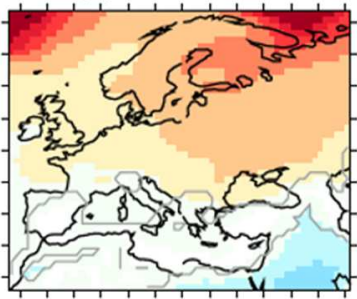

(f) FGOALS-s2

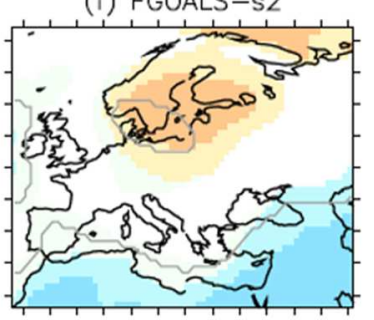

(j) MRI-CGCM3

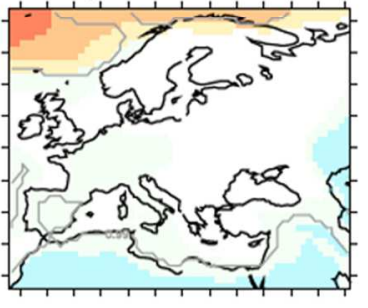

(m) CMIP5 ens.mean (c) CSIRO-Mk3-6-O

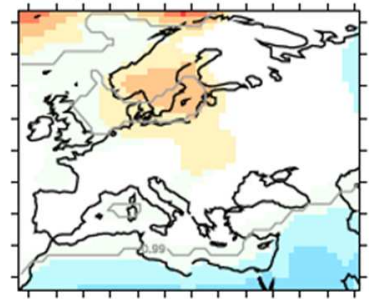

(g) MIROC-ESM

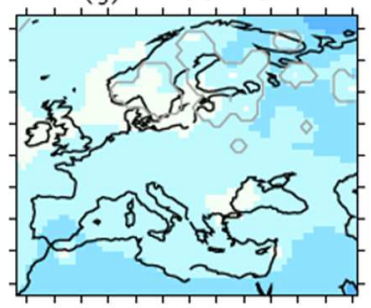

(k) GISS-E2-R

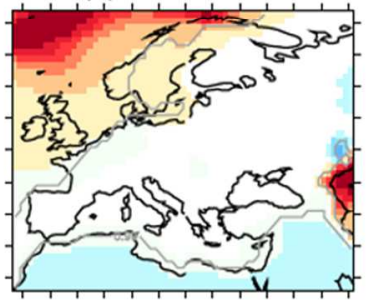

(n) Reconstruction

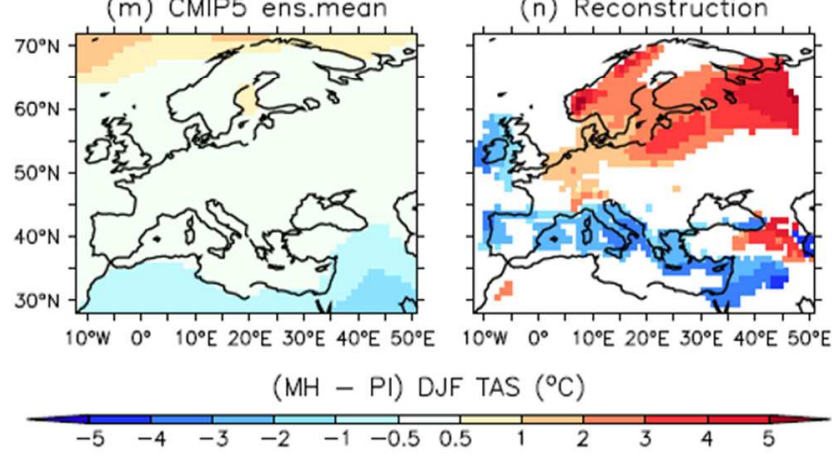

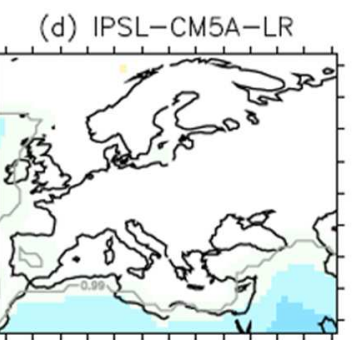

(h) HadGEM2-ES

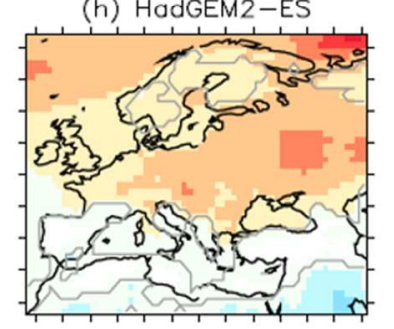

(I) $\operatorname{ccs} 4$

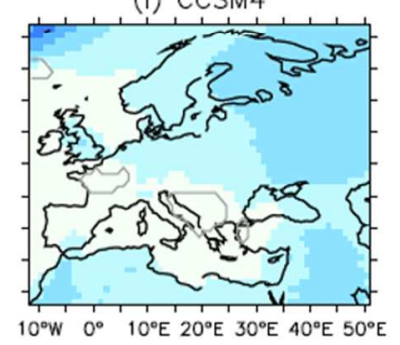

167 Figure 2: (a)-(l) Significant differences (color: at 90\% confidence level; inside contours: at 99\% confidence

168 level) between mean wintertime near-surface air temperature (SAT) in mid-Holocene and pre-industrial

169 simulations run with 12 different climate models; (m) Multi-model ensemble mean difference between MH and

170 PI climatological wintertime SAT; (n) Mauri et al. (2014) reconstruction of the MH climatological wintertime

171 SAT anomaly - only data where the signal is larger than the estimated uncertainty is considered. 


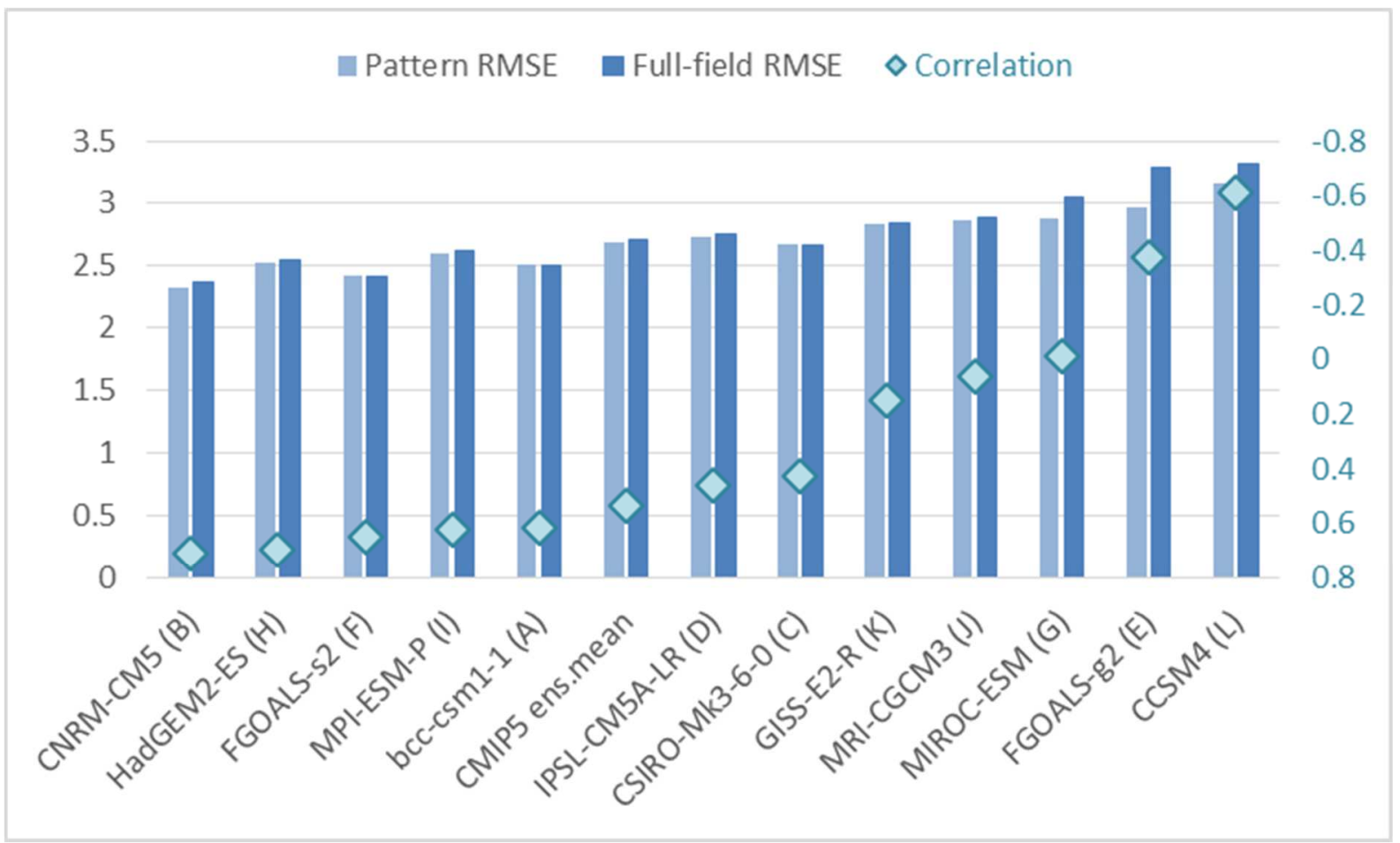

173

174 Figure 3: Statistics comparing the simulated and reconstructed (Mauri et al. 2014) mid-Holocene wintertime

175 SAT anomalies over Europe. Correlation (values shown on the right-side vertical axis): spatial correlation

176 coefficient between the two fields compared; Pattern RMSE: root-mean-square error when the respective spatial

177 average has been removed from each of the two fields compared; Full-field RMSE: total root-mean-square-

178 difference between the two fields. The model data, including the multi-model ensemble mean, are sorted from

179 the highest to the lowest spatial correlation with the reconstructed data. The statistics are only calculated using

180 those grid points where the reconstructed signal is stronger than the estimated uncertainty (see Figure $2 n$ ).

181 Some models fail to represent the reconstructed $\Delta$ SAT $_{\mathrm{DJF}}$, Eu pattern, like CCSM4, FGOALS-

182 g2 and MIROC-ESM, which show near-zero or negative spatial correlation coefficients with

183 the reconstructed field and RMSEs larger than $3^{\circ} \mathrm{C}$. Other models like CNRM-CM5 and

184 HadGEM2-ES have some success in simulating a similar pattern, i.e., a positive north-south

185 temperature anomaly gradient (spatial correlation coefficient $\sim 0.7$ ) but still fail at simulating

186 the reconstructed amplitude (pattern $\mathrm{RMSE} \geq 2.3^{\circ} \mathrm{C}$ ), and the temperature anomalies

187 themselves (full-field RMSE $\geq 2 \cdot 4^{\circ} \mathrm{C}$ ). 
188 In terms of latitudinal gradient, Figure 4 shows the zonal mean anomalies of wintertime

189 temperatures over continental Europe in the models compared to the reconstruction. This

190 figure clearly shows that all the models do not reproduce the amplitude of the dipole between

191 northern and southern Europe. It also shows that the uncertainty in the temperature

192 reconstruction is large and there are three models that are within the error bar of the

193 reconstruction for this diagnostic for more than $95 \%$ of the latitude range considered: CNRM-

194 CM5, FGOALS-s2 and bcc-csm1-1. The first two are also in the top three for the RMSE and

195 correlation (cf. Figure 3). This shows that some models succeed in reproducing the

196 reconstruction latitudinal gradient when considering the uncertainty in the reconstruction,

197 although with a lower amplitude as compared to the best guess. We also notice that the

198 precise pattern is usually not perfectly reproduced (e.g. cooling signal over Ireland in the 199 reconstruction).

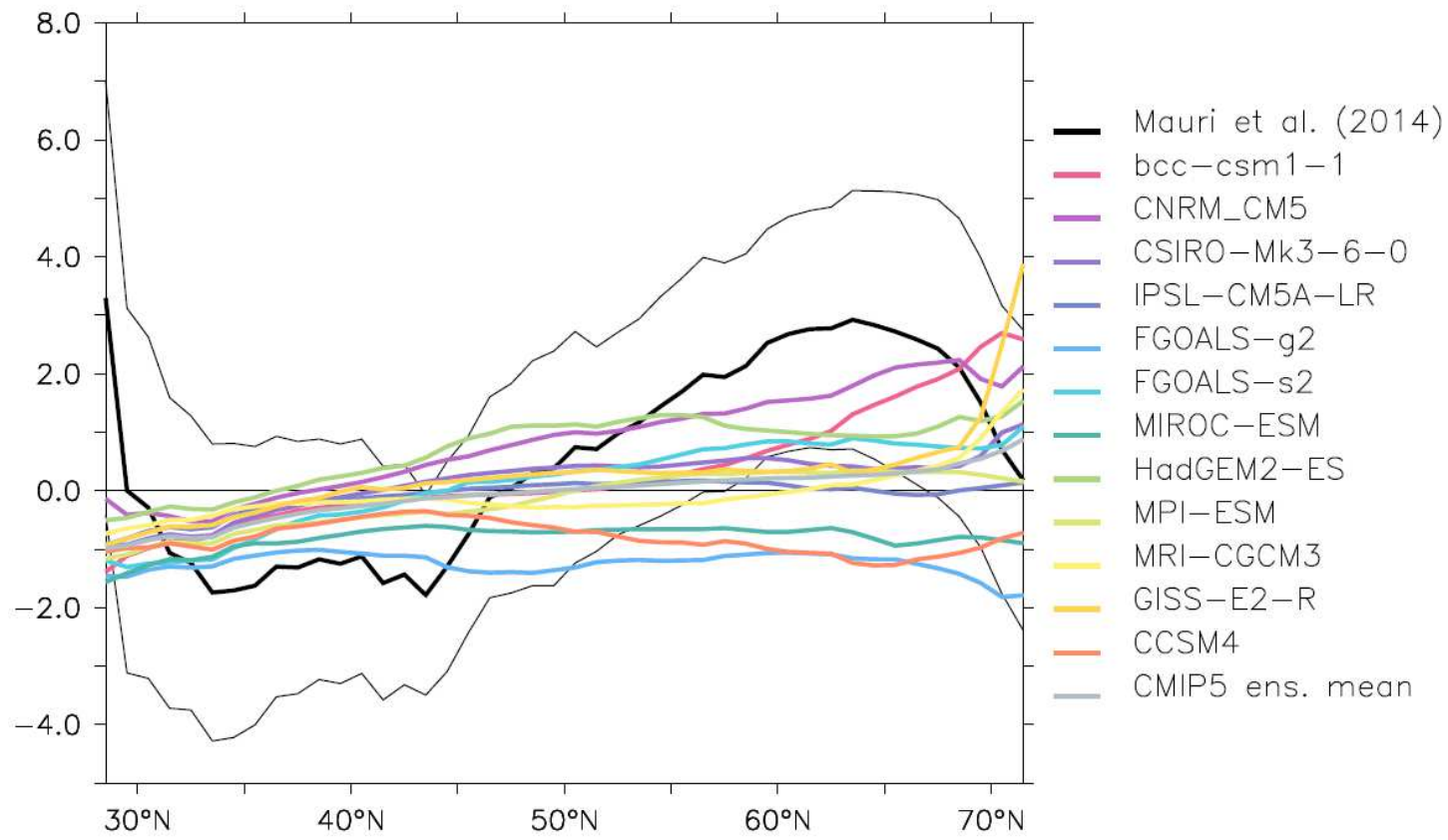

200 Figure 4: Zonal means of the climatological wintertime temperature anomalies over Europe - model results vs.

201 Mauri et al. (2014) reconstruction. The reconstruction is shown in black (thick line) with its associated

202 uncertainty (thin lines). The different models are shown in color and the model ensemble mean is shown in grey.

203 All model data have been regridded onto the reconstruction data grid and the same (reconstruction) land-sea

204 mask was applied before the calculation of the zonal means. 


\section{MH winter atmospheric circulation anomalies in the PMIP3 models}

207 Mauri et al. (2014) proposed that the MH temperature anomaly pattern over Europe could be 208 caused by a NAO-like atmospheric circulation anomaly. To explore this possibility in the 209 PMIP3 database, Figure 5 shows the statistically significant sea-level pressure differences 210 ( $\triangle \mathrm{SLP}$ ) between the climatological wintertime (DJF) MH and PI simulations over the North 211 Atlantic (NA) sector for the 12 analyzed models. All models show significant MH winter SLP 212 anomalies, of the order of $0.5-1.5 \mathrm{hPa}$, with corresponding 1000-hPa wind speed anomalies

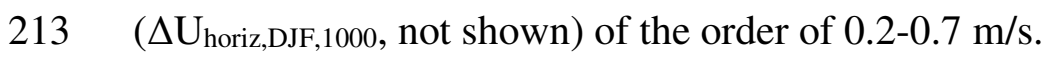

(a) bcc-csm $1-1$

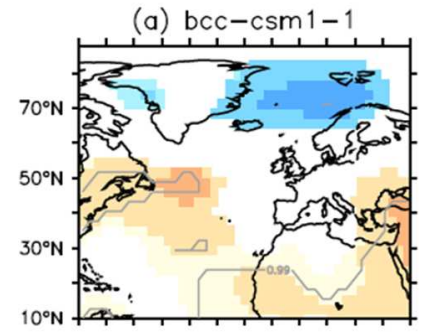

(e) FGOALS $-g 2$

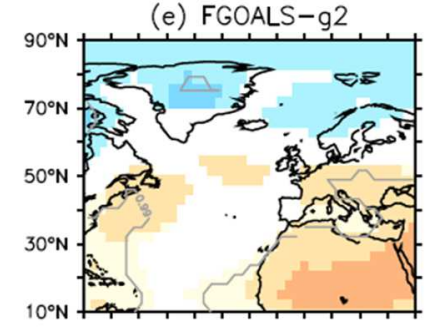

(i) MPI-ESM-P

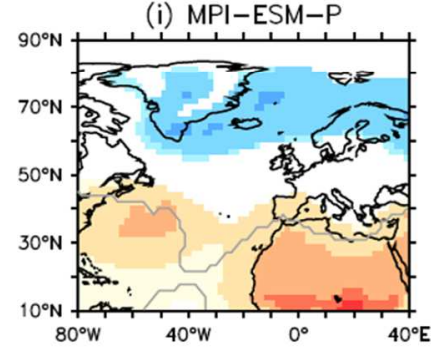

(b) CNRM-CM5

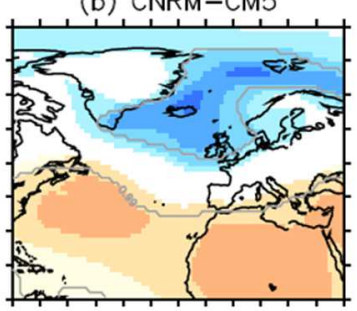

(f) FGOALS $-s 2$

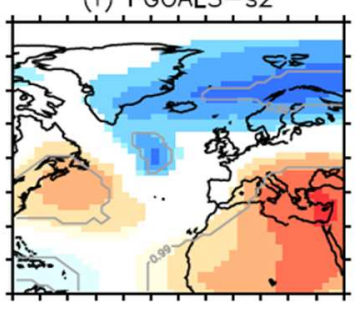

(j) MRI-CGCM3

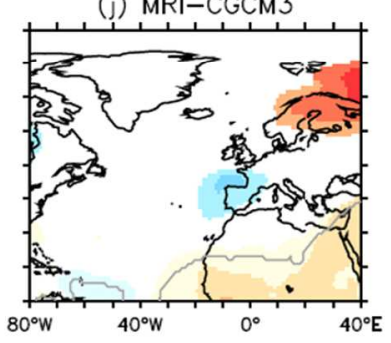

(c) CSIRO-Mk3-6-O

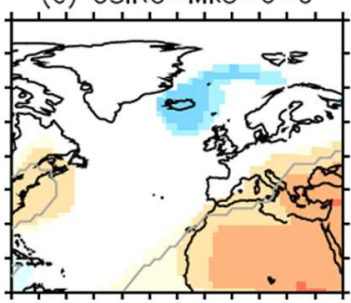

(g) MIROC-ESM

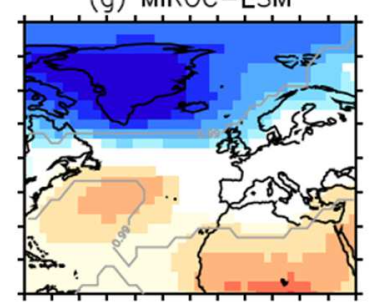

(k) GISS-E2-R

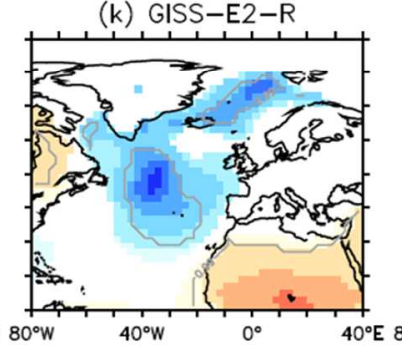

(d) IPSL-CM5A-LR

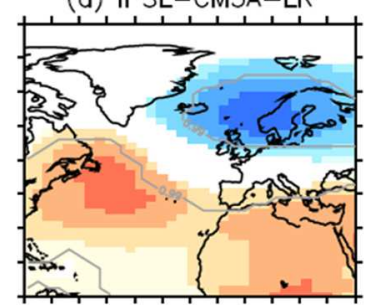

(h) HadGEM2-ES

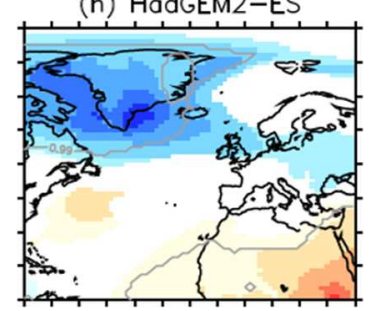

(I) CCSM4

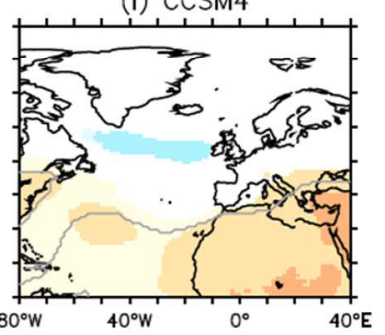

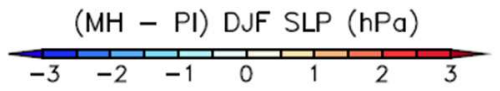

215 Figure 5: Significant differences (color: at 90\% confidence level; inside contours: at 99\% confidence

216 level) between mean wintertime sea-level pressure in mid-Holocene and pre-industrial simulations run 217 with 12 different climate models. 
218 Figure 6 shows the multi-model mean circulation anomalies at different levels in the 219 troposphere. Significant anomalies (two-sided independent sample t-test of significance of the 220 MH-PI difference using the last 200 years of each simulation or, where simulations were 221 shorter, all years of the simulations) at the $99 \%$ level are found at all atmospheric levels. The 222 most notable feature is a negative zonal wind speed anomaly in the subtropics (around $30^{\circ} \mathrm{N}$ ), 223 maximum at upper levels $\left(\Delta \mathrm{u}_{200}\right)$ and over the western half of the North Atlantic. This feature 224 is present and prominent in all models (with the exception of GISS-E2-R where the 225 significant anomaly is present, but much weaker than in the other models, not shown), but with structures varying in strength, extent and zonal orientation. We can trace it to a local weakening of the jet streams (in some models, accompanied by a slight northward shift of the eddy-driven jet) and, for most models, a more marked separation between the eddy-driven and subtropical jet streams over the North Atlantic (illustrated in Figure 6a for the multimodel ensemble mean). This results in an anticyclonic horizontal wind speed anomaly and local high pressure in the West Atlantic northward of the negative $\Delta \mathbf{u}_{200}$ region. For most models, this anticyclonic anomaly dominates the pattern of mean atmospheric circulation 233 change over the North Atlantic. In those cases, this anomaly structure is found throughout the 234 atmospheric column (as illustrated in Figures $6 \mathrm{~b}$ and $6 \mathrm{c}$ for the $500 \mathrm{hPa}$ level), down to the surface (Figure 6e), explaining the positive SLP anomalies found in most models over the southwestern North Atlantic (Figure 5, Figure 6d). Even the MRI model, which has no 237 significant anomalies in the lower atmosphere, shows a similar significant anomaly in the jet 238 stream (not shown).

239 While this positive pressure anomaly in the Western Atlantic has an equivalent barotropic 240 structure that extends throughout the troposphere, the positive SLP anomaly seen over North 241 Africa in the multi-model mean (Figure 6d) is on the contrary very shallow, disappearing or 242 even changing sign at $500 \mathrm{hPa}$. This baroclinic structure is linked to a cold temperature 243 anomaly in the atmospheric column, which can be explained by the negative DJF radiative 
244 forcing. The reduction of the radiative forcing is strongest at low latitudes (Figure 1), and has

245 a larger impact over continental regions like North Africa.

(a) DJF $200 \mathrm{hPa}$ Horizontal wind speed

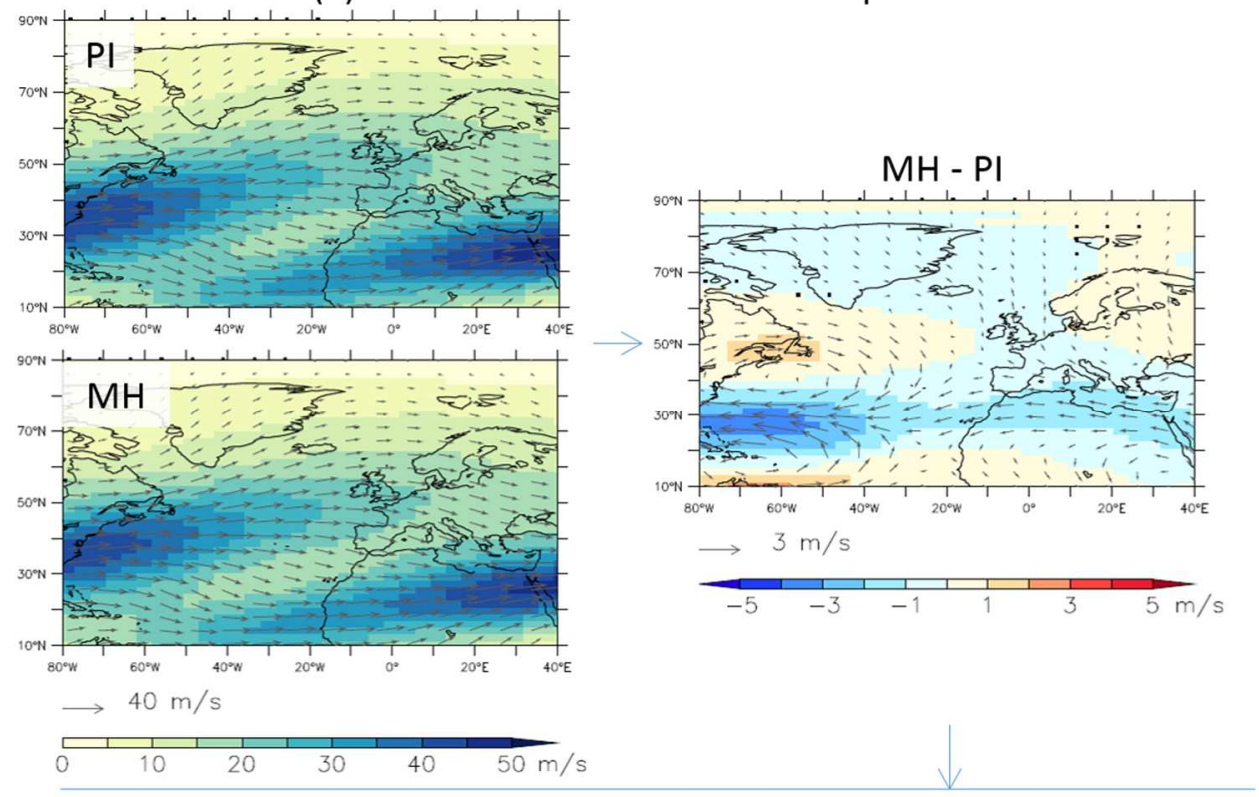

(b) $(\mathrm{MH}-\mathrm{PI}) \mathbf{Z 5 0 0}$

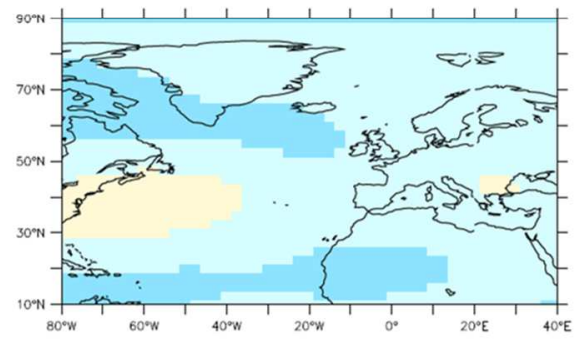

(c) $(\mathrm{MH}-\mathrm{PI}) 500 \mathrm{hPa}$ Horiz. wind speed

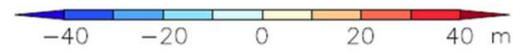

(d) $(\mathrm{MH}-\mathrm{PI})$ SLP
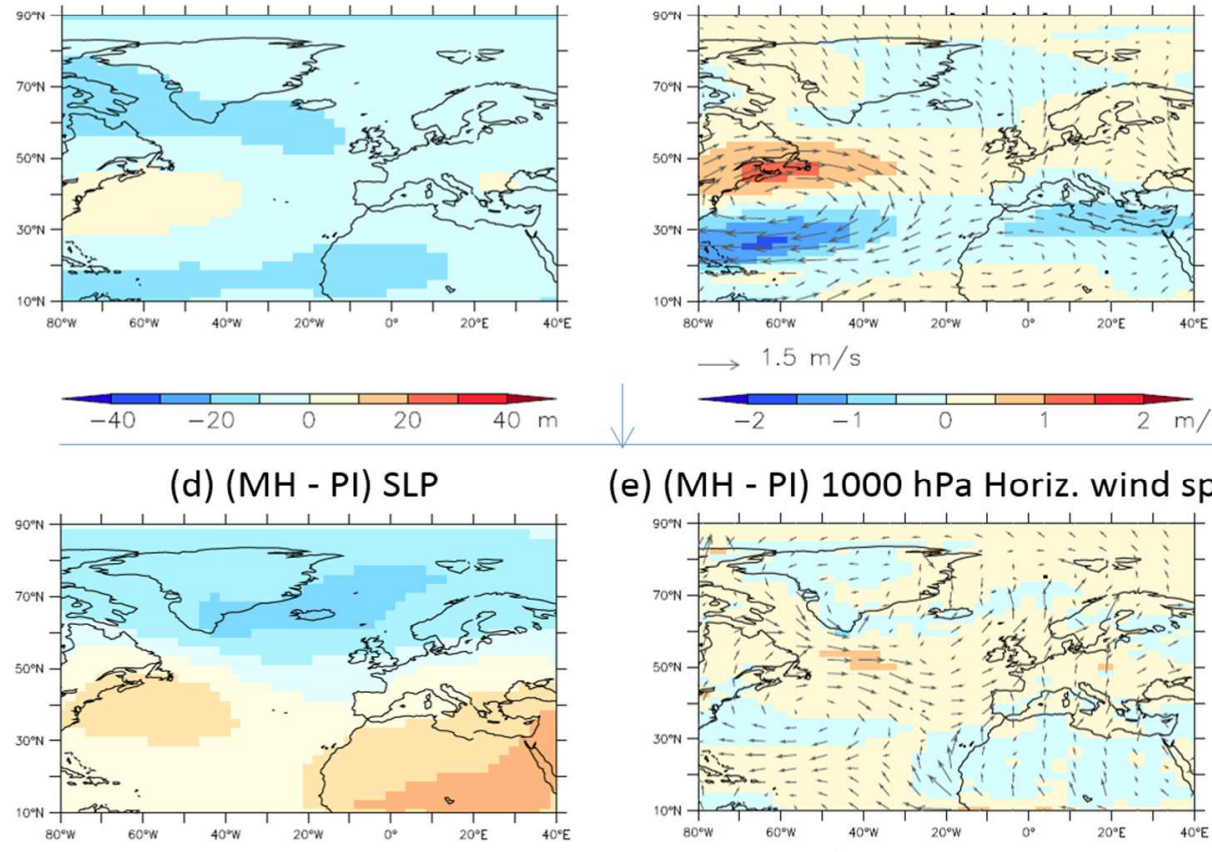

$\longrightarrow 1.5 \mathrm{~m} / \mathrm{s}$

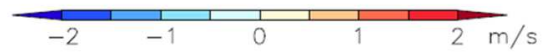

(e) (MH - PI) 1000 hPa Horiz. wind speed

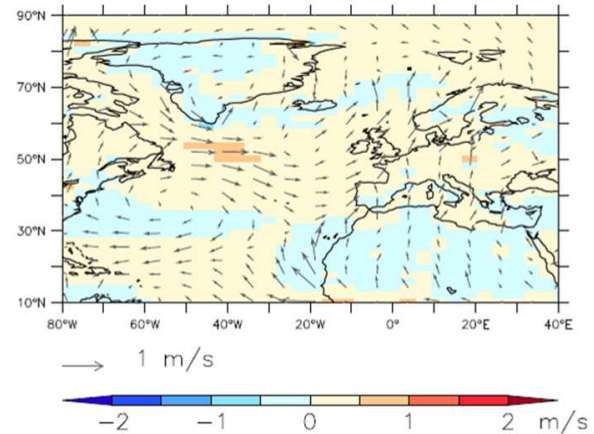

247 Figure 6: Multi-model ensemble mean wintertime: (a) $200 \mathrm{hPa}$ horizontal wind speed in pre-industrial (PI), mid-

248 Holocene $(\mathrm{MH})$ simulations and the corresponding MH-PI difference; (b) $500 \mathrm{hPa}$ geopotential height $\mathrm{MH}$ anomaly; (c) $500 \mathrm{hPa}$ horizontal wind speed anomaly; (d) sea-level pressure anomaly; (e) $1000 \mathrm{hPa}$ horizontal 
(based on the last 200 years or, where shorter, on the full time series of the MH and the PI simulations, respectively), for each model. For each model, we have found significant MH-PI differences at the 99\% confidence level. The anomaly patterns were very similar from one model to the other, which allowed us to present the anomaly maps for the multi-model ensemble as representative of the ensemble of models.

\section{5}

\section{Atmospheric circulation vs. European temperature anomaly patterns}

Figure 5 shows that several PMIP3 models simulate a positive SLP anomaly over the southern part of the North Atlantic and a negative SLP anomaly over the northern part of the basin during $\mathrm{MH}$ winters. This pattern could be roughly construed to be $\mathrm{NAO}^{+}$-like, as Mauri et al. 259 (2014) argued could cause their reconstructed DJF $\Delta \mathrm{SAT}_{\mathrm{EU}}$ pattern. This section examines 260 whether such a relationship between a $\mathrm{NAO}^{+}$-like circulation anomaly and a $\triangle \mathrm{SAT}_{\mathrm{EU}}$ pattern can be found within our multi-model ensemble.

A key question is whether the differences between the simulated temperature anomaly patterns between models can be attributed to the differences in their simulated atmospheric circulation anomalies over the North Atlantic. More specifically, we want to assess whether the models that simulate a positive north-south temperature gradient over Europe are only the models that also simulate a $\mathrm{NAO}^{+}$-like circulation anomaly over the North Atlantic.

267 A qualitative comparison of Figure 2 and Figure 5 indicates that this is not the case. While the 268 hypothesis of a $\mathrm{NAO}^{+}$-like cause of marked north-south gradients in $\triangle \mathrm{SAT}_{\mathrm{DJF}}$, EU could hold 269 for a few models (e.g., CNRM-CM5), the ensemble of models does not support it. Some 270 models exhibit a $\mathrm{NAO}^{+}$-like circulation without a strong north-south $\triangle \mathrm{SAT}_{\mathrm{DJF}}$, EU gradient 271 (e.g., IPSL-CM5A-LR, MIROC-ESM), while other models show a marked $\Delta \mathrm{SAT}_{\mathrm{DJF}}$, EU 272 gradient without simulating a $\mathrm{NAO}^{+}$-like circulation anomaly (e.g., GISS-E2-R). For some 273 model simulations showing a negative SLP anomaly around Iceland, which can look like part 274 of a $\mathrm{NAO}^{+}$pattern, just like over Africa the pressure anomaly disappears with height (not 275 shown), and is most likely a thermal structure caused by the local warming at the surface. 
For a quantitative assessment, Figure 7 evaluates the relationship between first-order indices

277 of the large-scale temperature and circulation changes, namely the north-south $\Delta \mathrm{SAT}_{\mathrm{DJF}}$, EU 278 gradient and the $\mathrm{NAO}^{+}$-like $\Delta \mathrm{SLP}_{\mathrm{NA}}$. The north-south $\triangle \mathrm{SAT}_{\mathrm{DJF}}$, Eu gradient is defined as the 279 mean temperature difference between a northern and a southern region over Europe chosen to 280 approximately reflect the Arctic Oscillation signature on SATEU, as shown in Mauri et al. 281 (2014) (top left panel in Figure 7 below). The $\mathrm{NAO}^{+}$-like $\Delta \mathrm{SLP}_{\mathrm{NA}}$ is defined as the mean sea282 level pressure difference between regions chosen to approximately reflect the centers of 283 action of the North Atlantic Oscillation index ( $c f$. Hurrell \& Deser 2010 - bottom right panel 284 in Figure 7). The scatterplot between the two indices in the top right panel of Figure 7 shows 285 a lack of significant correlation that confirms that the PMIP3 models do not support a 286 straightforward link between $\mathrm{MH}$ temperature anomaly patterns over Europe and a $\mathrm{NAO}^{+}$-like circulation anomaly over the North Atlantic.
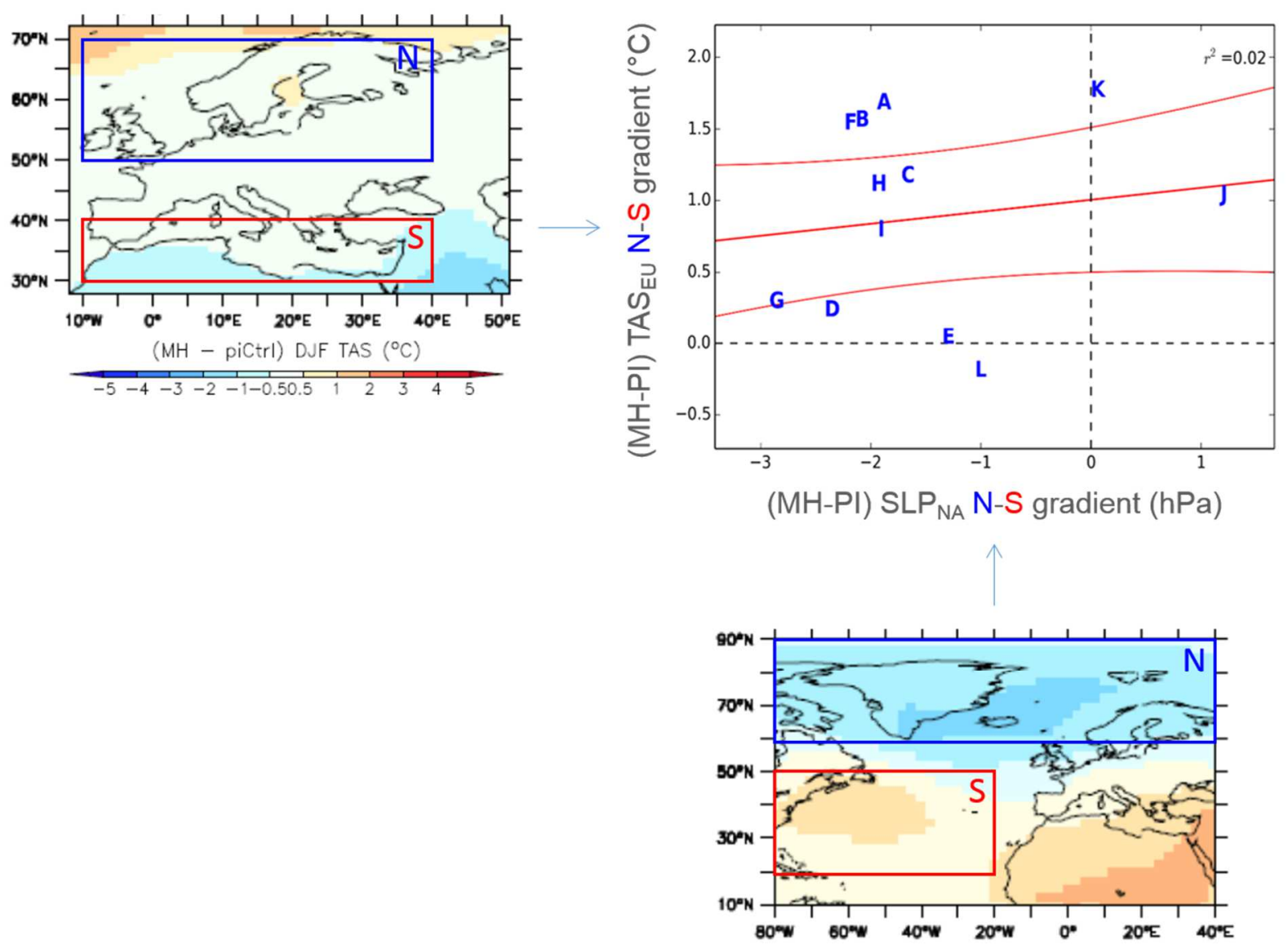

(MH - piCtrl) DJF SLP (hPa) 
Figure 7: Top left: PMIP3 ensemble mean anomalies of SAT (in ${ }^{\circ} \mathrm{C}$ ) in DJF for MH minus PI. The blue box defines the northern region and the red box, the southern region used for calculating the north-shout SAT gradient. Bottom right: PMIP3 ensemble mean anomalies of SLP (in hPa) in DJF for MH minus PI. The blue box defines the northern region and the red box, the southern region used to define the SLP north-south gradient. Top right: Multi-model relationship of the land temperature anomaly gradient (defined in top left panel) - on the $\mathrm{y}$-axis - and the SLP anomaly gradient (defined in bottom right panel) - on the x-axis. The squared correlation coefficient is shown in the top-left corner of the figure. The red lines indicate the linear regression and the 95\% confidence interval for this regression.

\section{Factors determining the simulated $\Delta$ SATDJF,EU meridional gradients}

Figure 2 shows that the strongest $\Delta \mathrm{SAT}$ DJF, EU signals are found, for most models, close to the latitude boundaries of the region considered. Enlarging the domain of our analysis places the European temperature anomalies patterns in the larger-scale context (Figure 8a). We find that

301 the modeled north-south $\Delta \mathrm{SAT}_{\mathrm{DJF}}$, EU contrasts are dominated, to the north, by warm

302 temperature anomalies over the Nordic Seas and, to the south, by cold temperature anomalies over northern Africa. This pattern resembles the reconstruction of the North-South contrast, but there are a number of regional differences. Most notably, the cooling pattern over Ireland is not captured by the climate models, while the warming from the ocean does not penetrate enough inland over Europe.

To a large extent, the negative SAT anomalies over northern Africa (and the positive SLP anomalies) are related to the negative radiative forcing in winter at these latitudes (Figure 1). This anomaly is strongest at low latitudes and has an amplified effect on SAT over continents

310 vs. oceanic regions, possibly due to the lower heat capacity of land than water and to the 311 differences in lapse rates between land and ocean (e.g. Joshi et al 2008).

312 Inter-model differences of $\triangle \mathrm{SAT}$ over the southern region in Figure $7 \mathrm{a}$ are indeed small $313\left(0.3^{\circ} \mathrm{C}\right.$ inter-model standard deviation) relative to the ones over the northern region $\left(0.8^{\circ} \mathrm{C}\right)$, 314 consistent with a lower $\triangle \mathrm{SAT}$ inter-model standard deviations over northern Africa than over 
315 the Nordic Seas (Figure 8b). Thus, for the rest of the paper we will focus mainly on what

316 determines the inter-model spread in $\Delta \mathrm{SAT}_{\mathrm{DJF}}$ over the Nordic Seas, that dominates the north-

317 south contrast.

(a) $\triangle$ TAS ens. mean

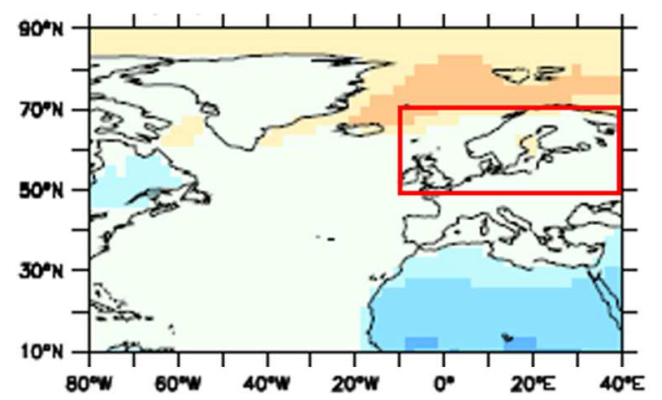

$\left(\mathrm{MH}-\right.$ piCtrl) DJF TAS $\left({ }^{\circ} \mathrm{C}\right)$ (b) $\triangle$ TAS ens. $\sigma$

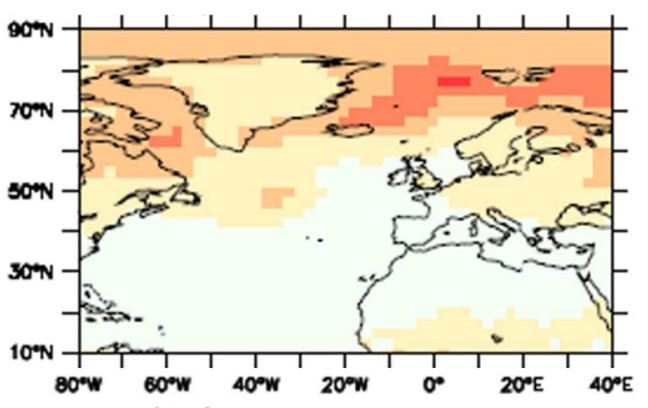

$\begin{array}{lll}3 & 4 & 5\end{array}$ (c) $\triangle$ SIC ens. mean

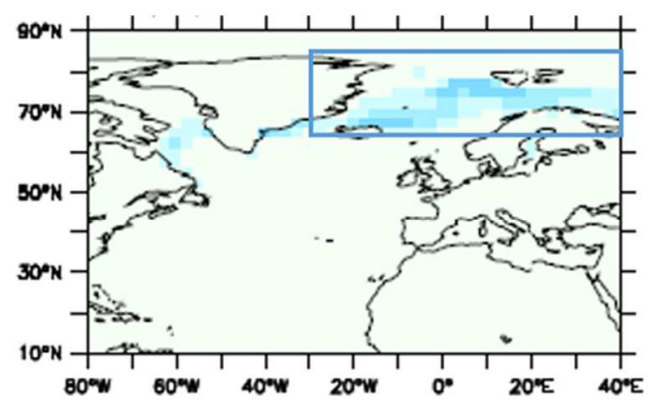

(MH - piCtrl) DJF SIC (\%) (d) $\triangle \mathrm{SIC}$ ens. $\sigma$

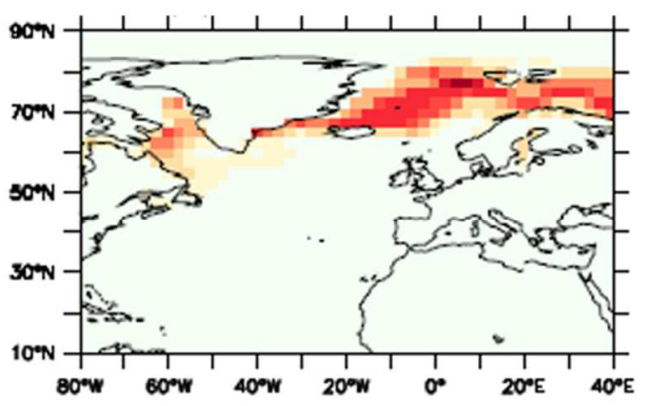

20 (e) $\Delta \mathrm{SIC}_{\mathrm{NS}}$ vs. $\Delta \mathrm{TAS}_{\mathrm{NEU}}$

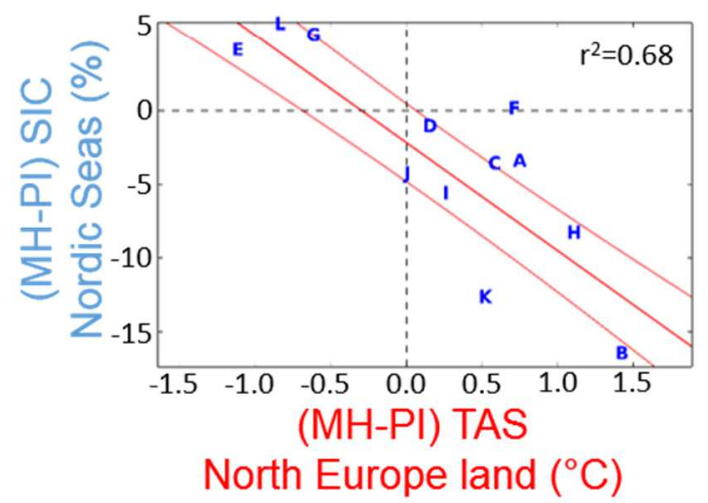

(f) $\Delta \mathrm{LH}_{\mathrm{NS}}$ vs. $\Delta \mathrm{TAS}_{\mathrm{NEU}}$

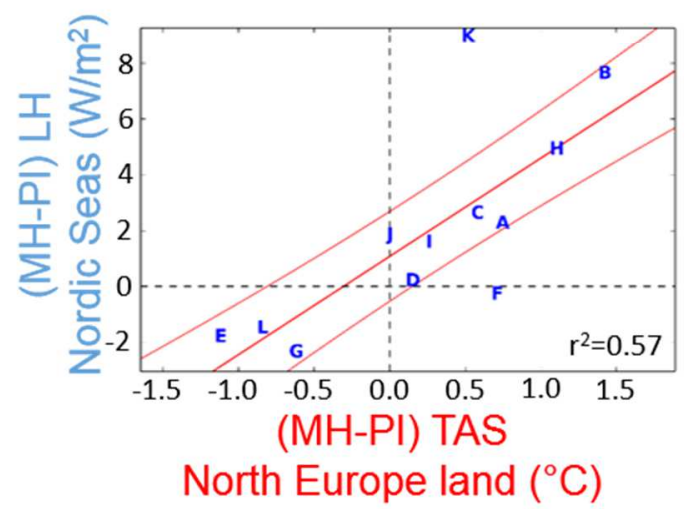

319 Figure 8: $\mathrm{MH}$ winter anomalies of $(\mathrm{a}, \mathrm{b})$ near-surface air temperature and (c- d) sea ice cover over the North 
standard deviation. (e) Relationship between simulated near-surface air temperature over land in northern Europe

322 and sea ice cover anomalies averaged over the region highlighted in (a) and (c) for the 12 models analyzed. (f)

323 Same as (e) but with sea ice cover anomalies replaced by latent heat flux anomalies from the ocean to the

324 atmosphere. The squared correlation coefficient is show in the top- and, respectively, bottom-left corner of the 325 plots. In both plots, the red lines indicate the linear regression and the 95\% confidence interval for the regression.

The spatial patterns of both the $\Delta \mathrm{SAT}_{\mathrm{DJF}}$ signal in the Nordic Seas and its inter-model spread

(Figure 8a, b) are strongly reminiscent of those of the DJF sea-ice cover anomalies (Figure 8c,

d). Sea-ice cover changes have a strong impact on near-surface temperatures via air-sea fluxes and albedo feedbacks (Swingedouw et al. 2006, Årthun et al. 2017). This influence extends to neighbouring land regions: the inter-model differences in $\Delta \mathrm{SAT}_{\mathrm{DJF}}$ in land areas of northern Europe (Figure 8e) are well correlated $\left(\mathrm{r}^{2}=0.68, \mathrm{p}<0.01\right)$ with the differences in $\triangle \mathrm{SIC}_{\mathrm{DJF}}$ Over

332 the Nordic Seas. Furthermore, these differences in $\Delta \mathrm{SAT}_{\mathrm{DJF}}$ are also well correlated with the 333 changes in latent heat flux from the ocean to the atmosphere over the Nordic Seas. Thus, we 334 argue that it is the difference in latent heat flux released in winter by the ocean to the 335 atmosphere and associated with the insulation effect of the presence (or not) of sea ice that explains the response of $\Delta \mathrm{SAT}_{\mathrm{DJF}}$ over northern Europe land. A similar mechanism was

337 indeed highlighted by Årthun et al. (2017) to explain the impact of Nordic Seas SST 338 variability on the temperature of Scandinavia.

339 Thus, to understand the differences between the wintertime $\mathrm{MH}$ European temperature 340 anomalies between the models, we mainly need to understand the origins of the differences 341 between the simulated sea ice cover anomalies in the Nordic Seas region.

\section{Origins of winter sea-ice decline}

\section{Atmospheric circulation anomalies}

344 While NAO-like anomalies do not directly determine the inter-model differences in winter 345 temperature anomalies over Europe in PMIP3 ensemble, atmospheric circulation changes 
between $\mathrm{MH}$ and PI winters could potentially control the sea ice anomalies in the Nordic

347 Seas, through anomalous atmospheric heat transport.

348 To test this hypothesis, we tried to calculate the total atmospheric heat transport into the

349 Nordic Seas region. This computation should be based on changes of both the mean and 350 transient circulation. Unfortunately, the PMIP3 database does not routinely include data at 351 sufficiently high frequencies to allow for the calculation of the latter term, nor does it provide 352 estimates of atmospheric heat transport computed at the model time step. We can thus only 353 offer a partial answer, related to the mean wind anomalies only.

354 Whether we consider the near-surface horizontal temperature advection due solely to the 355 change in the mean winter near-surface horizontal wind velocities between PI and MH 356 (estimated as $-\Delta \vec{U} \cdot \nabla T_{P I}$, where $\Delta$ stands for MH-PI differences, $\vec{U}$ for the horizontal wind 357 velocity and $T_{P I}$ for the temperature for pre-industrial simulation; Figure 9) or the change 358 between the mean circulation-induced horizontal temperature advection in PI vs. MH winters 359 (estimated as $-\Delta(\vec{U} \cdot \nabla T)$; not shown), we find no correlation of these respective anomalies 360 with the winter sea ice cover anomaly over the Nordic Seas region (Figure 9). More generally, 361 two other elements of the energy budget argue against an increased poleward atmospheric 362 transport in $\mathrm{MH}$ winter: at the top of the atmosphere, the latitudinal gradient of insolation 363 decreases (with more cooling at lower latitudes), and the ocean heat transport tends to 364 increase (due to AMOC strengthening as shown below). Both would typically lead to a 365 compensating equatorward energy transport by the atmosphere, away from the sea ice region. 366 Such a response has actually been demonstrated in $\mathrm{MH}$ simulations run with the IPSL367 CM5A-LR model (Saint-Lu et al. 2016). We thus find no evidence that the changes in the atmospheric heat transport may be responsible for $\Delta \mathrm{SIC}_{\mathrm{DJF}}$ in the models. 


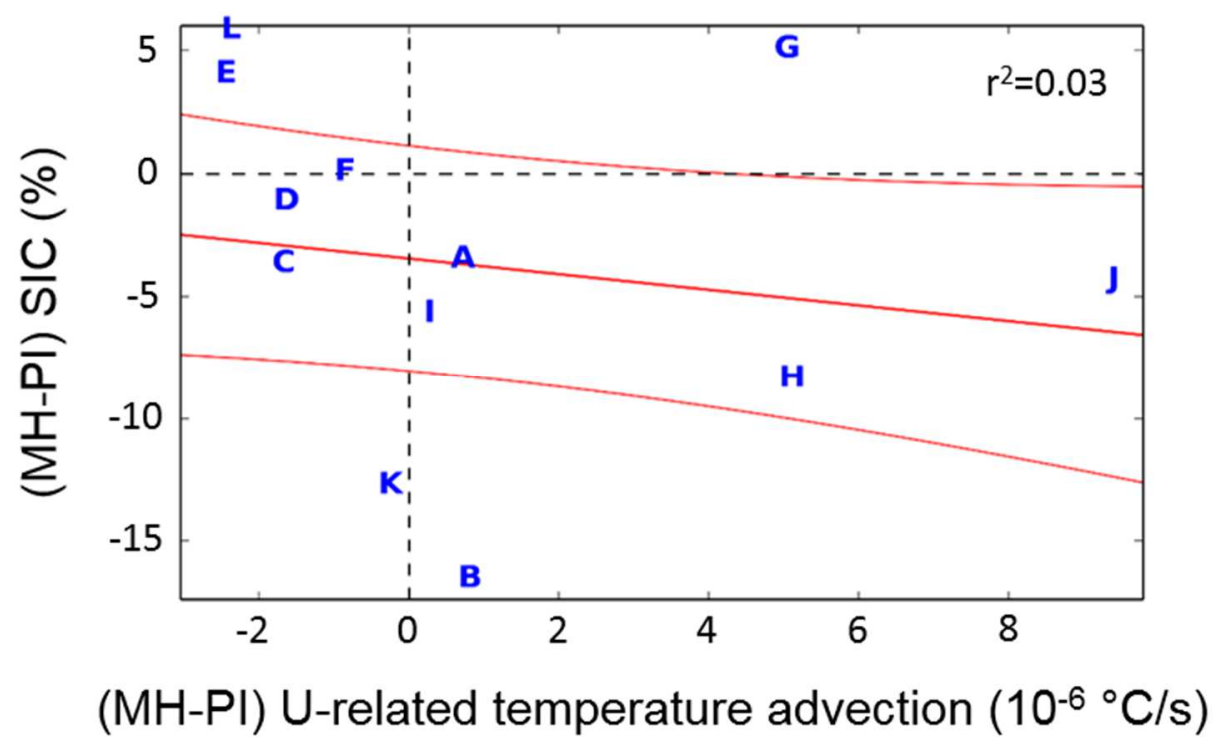

370 Figure 9: Multi-model relationship between wintertime sea ice cover anomalies and mean 1000hPa horizontal

371 circulation anomaly-related temperature advection in the NS region. The red lines indicate the linear regression 372 and the $95 \%$ confidence interval for this regression.

\section{Summer sea ice anomalies}

374 Another potential source of the inter-model differences in winter sea ice anomalies is the 375 summer (JJA) sea ice response, with a memory effect between the two seasons. Indeed, the 376 insolation is far larger in the Mid-Holocene compared to the pre-industrial period during summer (Figure 1), potentially leading to large melting of sea ice and heat storage in the ocean in summer, which may then persist into winter due to the large inertia of the ocean. There is a fine interplay between winter and summer sea ice: winter sea ice thickness heavily 380 influences the ice pack vulnerability to summer melt, and thus has an important effect on 381 summer sea ice cover (Berger et al. 2013). Conversely, summer melt allows for ocean surface heat uptake and renders new sea ice formation more difficult during autumn and winter. Thus, we can also expect a $\Delta \mathrm{SIC}_{\mathrm{JJA}}$ effect on $\Delta \mathrm{SIC}_{\mathrm{DJF}}$ (Berger et al. 2013). This latter effect may 384 play an important role in determining the inter-model $\Delta \mathrm{SIC}_{\mathrm{DJF}}$ differences. Indeed, the 385 different models may exhibit different sea ice responses to the summer radiative forcing 386 (Figure 1) for example through different strength of feedbacks, like the local cloud response 

the winter responses.

We thus check if the relationship between $\Delta \mathrm{SIC}_{\mathrm{JJA}}$ and $\Delta \mathrm{SIC}_{\mathrm{DJF}}$ is consistent between the models. Figure 10 indeed shows a strong multi-model relationship between $\Delta \mathrm{SIC}_{\mathrm{JJA}}$ and $\Delta \mathrm{SIC}_{\mathrm{DJF}}$, both globally over the Northern Hemisphere high latitudes $\left(\mathrm{r}^{2}=0.74, \mathrm{p}<0.01\right)$, and regionally over the Nordic Seas $\left(r^{2}=0.73, \mathrm{p}<0.01\right)$.

(a) Northern Hemisphere high latitudes $\left(>60^{\circ} \mathrm{N}\right)$

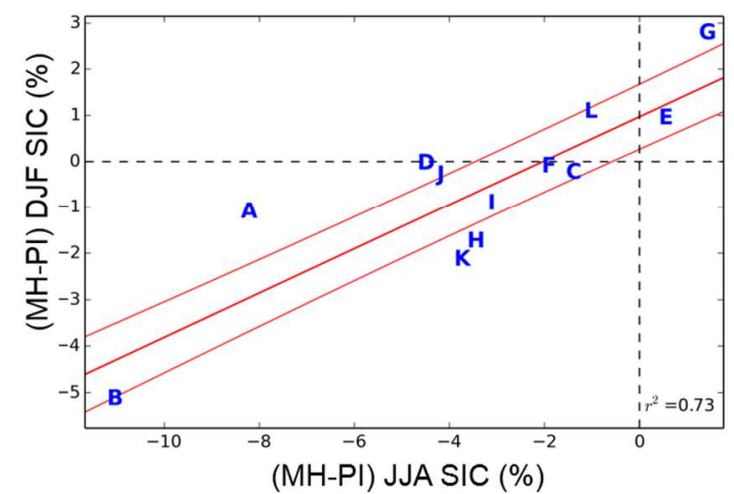

(b) Nordic Seas

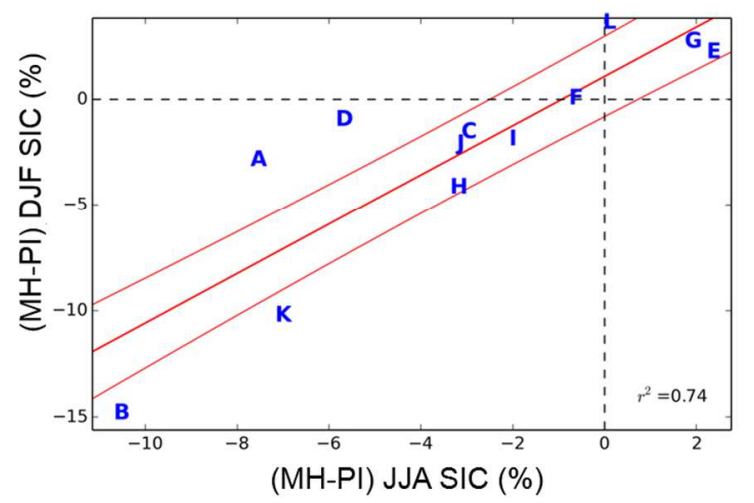

393

394

Figure 10: Relationship between $\mathrm{MH}$ winter and summer sea ice cover anomalies (a) averaged over the Northern Hemisphere high latitudes (above $60^{\circ} \mathrm{N}$ ); (b) averaged over the Nordic Seas (rectangular region contoured in Figure 8a, c). The text boxes in the bottom-left corner of the figures show the associated squared correlation coefficients. The red lines indicate the linear regressions and the $95 \%$ confidence interval for the regressions.

While it is likely that a memory of the seasonally forced $\Delta \mathrm{SIC}_{\mathrm{JJA}}$ can influence $\Delta \mathrm{SIC}_{\mathrm{DJF}}$, it is also possible that both summer and winter sea ice anomalies are influenced by a large-scale, common factor such as a change in the Atlantic meridional overturning circulation (AMOC), which we investigate in the following section.

\section{Change in the AMOC}

Figure 11 shows the changes in the AMOC between the simulated MH and PI climates. All 12 models analyzed show significant anomalies in the mean AMOC, with considerable inter- 
model variability in terms of both anomalies (Figure 11, colors) and background state (PI

407 AMOC - Figure 11, contours). In general, the AMOC is strengthened in MH compared to PI.

408 This is consistent with Born et al. (2010), who proposed that for a climate with warmer

409 summer (the Eemian in their case), the decrease in sea ice transport through Fram Strait may

410 change the salinity in the Labrador Sea and enhance local convective activity, feeding a

411 stronger AMOC.

412 AMOC MH anomalies vary between models not just in terms of intensity, but also in terms of

413 structure, complicating their quantitative comparison. Nevertheless, maxima of the meridional

414 stream function have been shown to be strongly related to the meridional ocean heat transport

415 (e.g. Boning et al. 1995). Thus, they represent a reasonable parameter to consider in the 416 investigation of sea ice changes.

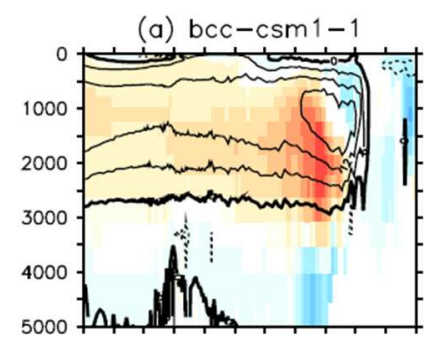

(e) FGOALS - g2

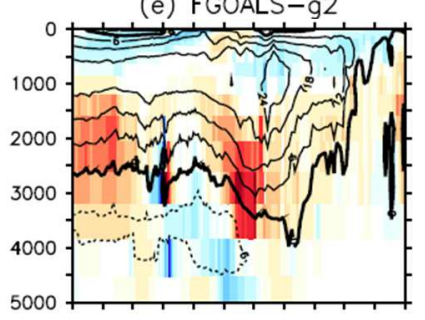

(i) $\mathrm{MPI}-\mathrm{ESM}-\mathrm{P}$

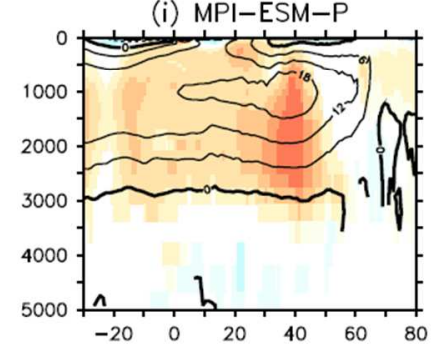

$(\mathrm{MH}-\mathrm{PI})$ ANM Atlanti (b) CNRM-CM5

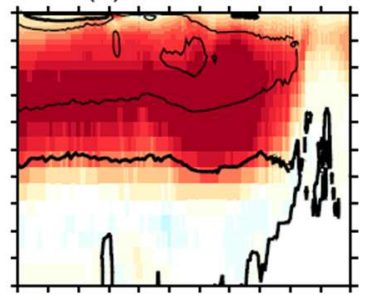

(f) FGOALS-s2

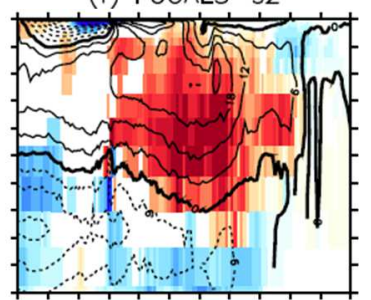

(j) MRI-CGCM3

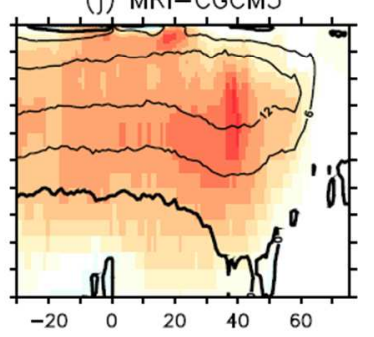

(c) CSIRO-Mk3-6-0

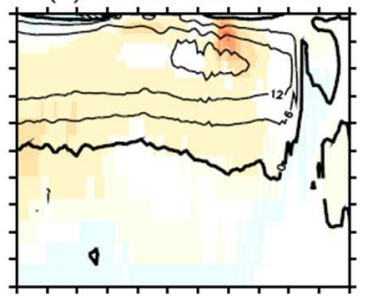

(g) MIROC-ESM

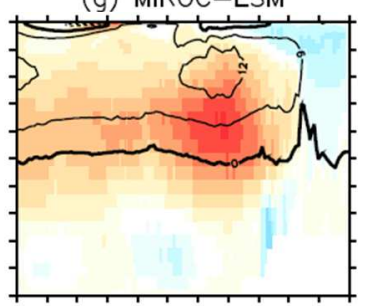

(k) GISS-E2-R

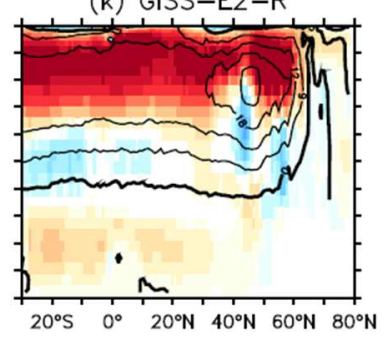

(d) IPSL-CM5A-LR

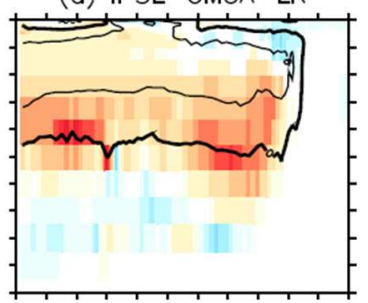

(h) HadGEM2-ES

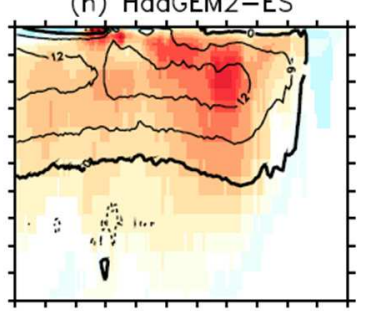

(I) CCSM 4

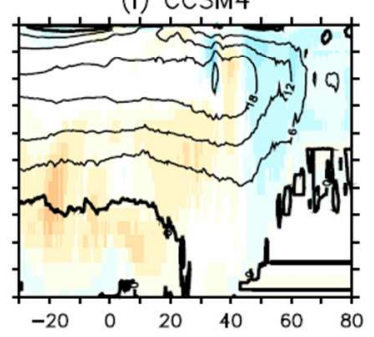


Figure 11: Color: significant (at 90\% level) MH anomalies of the climatological annual mean (ANM) Atlantic meridional stream function; contours: PI climatologies (contour spacing: $6 \mathrm{~Sv}$; solid/dashed contours represent positive/negative values) for the 12 models analyzed.

421

Figure 12 shows the relationship between winter sea-ice cover anomalies and anomalies in the maximum of the climatological Atlantic meridional stream function at three different latitudes: $26^{\circ} \mathrm{N}$ and $45^{\circ} \mathrm{N}$, typically used when describing the AMOC strength (e.g., Huck et al. 2008, McCarthy et al. 2015), and $60^{\circ}$ N, closer to the Nordic Seas region. The DJF SIC anomalies are in all cases negatively correlated with the AMOC strength anomalies. The correlation coefficient and the slope of the corresponding linear regressions increase with latitude, so that the strongest link of $\Delta \mathrm{SIC}_{\mathrm{DJF}, \mathrm{NS}}$ with the meridional ocean circulation is found for $\triangle \mathrm{AMOC}$ at $60^{\circ} \mathrm{N}$. The correlation coefficient is 0.89 (p-value $<0.01$ ) and the linear regression line has a near-zero intercept, indicating that, as would be expected, an intensification of the AMOC at high latitudes is linearly associated to negative SIC anomalies in the Nordic Seas and vice-versa. The correlation remains high even at $26^{\circ} \mathrm{N}(\mathrm{r}=0.75$, $\mathrm{p}<0.01$ ), indicating that this relationship is not a purely local effect. Nevertheless, the relationships we find are very sensitive to the low number of models, and removing a few of them can strongly lower the correlation.

Changes in the subpolar gyre may also strongly affect the heat transport to the high latitudes (Born et al. 2015). However, the barotropic stream function was not available for all the models, limiting the analysis of this effect. Since the strength of the subpolar gyre is closely related to the strength of the convection in the subpolar gyre (Born et al. 2015), we suggest that the changes in AMOC would also be reflected in subpolar gyre strength, both leading to an increase of meridional heat transport.

The changes in oceanic heat transport act on longer than seasonal time scales and may thus affect sea ice cover in both winter and summer, likely contributing to the correlation between 
443 winter and summer anomalies highlighted in former sub-section. Nevertheless, direct changes 444 in summer sea ice in response to changes in insolation are also due to regional sensitivity and 445 feedbacks that may differ among the models (e.g., Massonnet et al. 2012), and so could 446 remain a relatively independent factor from AMOC strengthening to explain the inter-model 447 spread. 

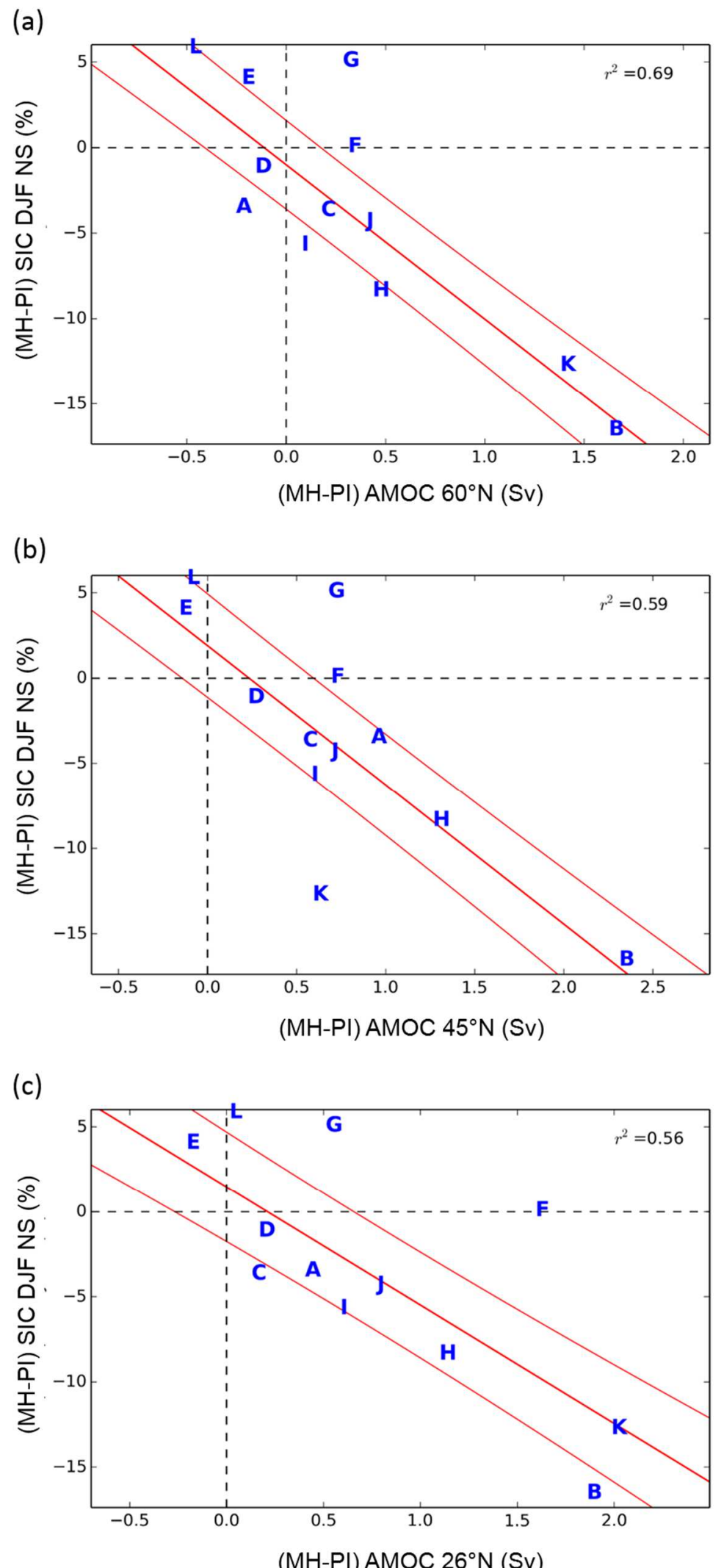

(MH-PI) AMOC $26^{\circ} \mathrm{N}(\mathrm{Sv})$

449 Figure 12: Relationship between mean winter MH sea ice cover anomalies over the Nordic Seas region and the

$450 \mathrm{MH}$ anomaly in the maximum climatological Atlantic meridional stream function at (a) $60^{\circ} \mathrm{N}$, (b) $45^{\circ} \mathrm{N}$ and (c)

$45126^{\circ} \mathrm{N}$. The squared correlation coefficients of the associated linear regressions are shown in the respective panels. 
452

453

454

The correlations are significant above the $99 \%$ level. The red lines indicate the linear regression and the $95 \%$ confidence interval for this regression.

\section{Combination of multiple factors}

In the previous subsections we analyzed one-to-one relationships between $\Delta \mathrm{SIC}_{\mathrm{DJF}, \mathrm{NS}}$ and a suite of atmospheric and oceanic variables. However, the inter-model differences in the winter sea ice anomalies are most likely explained by a combination of different factors which affect the sea ice cover in different measures depending on the model.

We have investigated a wide array of variable combinations to best explain the inter-model variations in $\triangle \mathrm{SIC}_{\mathrm{DJF}, \mathrm{NS}}$ through multiple linear regressions. We have considered parameters physically linked with the winter sea ice anomalies, like the temperature advection due to the mean circulation change in the Nordic Seas region, the surface downward radiative flux anomalies, the background state (PI) sea ice cover, the summer sea ice cover anomalies and the change in the AMOC strength.

The low number of climate simulations (12), the reductive framework (lack of sensitivity experiments) and the intrinsic high level of connectivity between climate variables through non-linear relationships (i.e., variables not independent) limit the potential of such a multivariate analysis. Nevertheless, some information can be distilled on the basis of this exercise.

While in most combinations and for most predictor variables, the high p-values associated to their respective coefficients did not allow for significant regressions, the p-values associated to the coefficient for the AMOC strength anomaly at $60^{\circ} \mathrm{N}$ were always very small (on the order of $10^{-4}-10^{-5}$ ) and the coefficients themselves were always found to be negative, indicating a robust effect of $\triangle \mathrm{AMOC}$ on $\triangle \mathrm{SIC}_{\mathrm{DJF}, \mathrm{NS}}$ in the direction already described in the former section. 
One multiple linear regression did yield significant results:

$$
\Delta S I C_{D J F, N S}=\alpha_{0}+\alpha_{1} \Delta A M O C_{\max .60^{\circ} N}+\alpha_{2} \Delta S I C_{J J A, N S}
$$

478 with $p_{\alpha_{0}}=0.04, p_{\alpha_{1}}=10^{-4}, p_{\alpha_{2}}=4 \cdot 10^{-5}$ and an adjusted $r^{2}$ of 0.96 .

479 Figure 13 shows the results of the multiple linear regression model in Eq. 1. Figure 13a shows 480 the good correspondence between the reconstructed and original $\Delta \mathrm{SIC}_{\mathrm{DJF}, \mathrm{NS}}$ and Figure $13 \mathrm{~b}$ 481 shows, for each model, the percentage of the sea ice cover change associated with each term 482 in the regression model. According to the model of Eq. (1), the summer sea ice anomalies and 483 AMOC strength anomalies have comparable effects on $\triangle$ SIC $_{D J F, N S}$, with the AMOC playing a 484 particularly important role in FGOALS-s2 and CCSM4, as well as in GISS-E2-R, HadGEM2485 ES, MRI-CGCM3, CNRM-CM5 and MPI-ESM-P where the AMOC term represents more 486 than $50 \%$ of the total change.

(a)

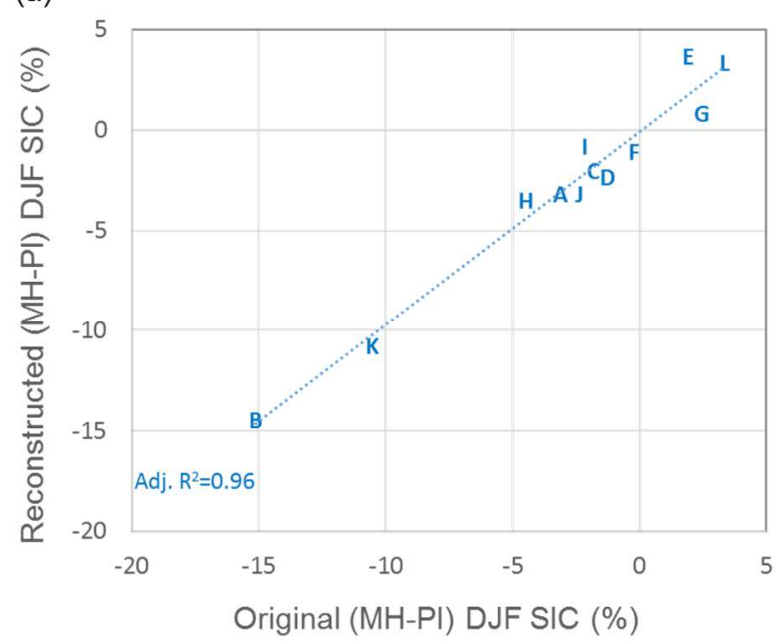

487

(b)

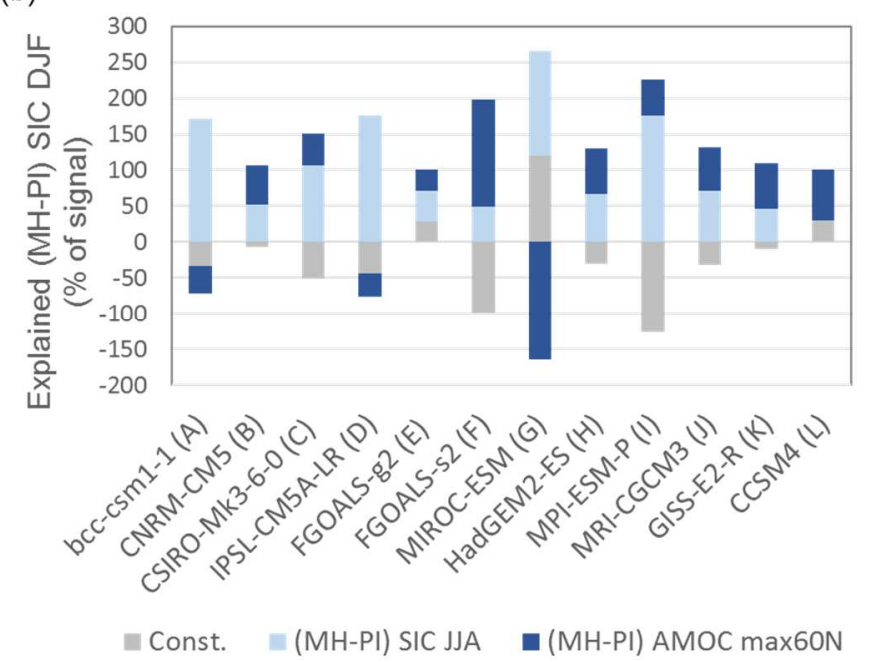

488 Figure 13. Results of the multiple linear regression of $\triangle \mathrm{SIC}_{\mathrm{DJF}, \mathrm{NS}}$ onto the $\mathrm{MH}$ anomaly of the AMOC maximum at $60^{\circ} \mathrm{N}$ and $\triangle \mathrm{SIC}_{\mathrm{JJA}, \mathrm{NS}}$ : (a) correspondence of the reconstructed and original $\Delta \mathrm{SIC}_{\mathrm{DJF}, \mathrm{NS}}$; (b) fraction of the simulated winter sea ice cover anomaly associated to each model predictor, for the 12 models analyzed. 
The adjusted $r^{2}$ can be mildly improved (to a value of 0.97 ) by adding the pre-industrial sea

492 ice cover over the Nordic Seas region, SICDJF,PI, NS, as an extra predictor. However, the associated p-value is 0.015 , indicating a $1.5 \%$ chance that this predictor has in fact no effect on $\Delta \mathrm{SIC}_{\mathrm{DJF}, \mathrm{NS}}$. Furthermore, the coefficient for this extra term is positive in this regression model (indicating that climate models where more winter sea ice is present in the Nordic Seas region in pre-industrial simulations tend to have positive or less negative Mid-Holocene 497 winter sea ice anomalies) but is negative in all other variable combinations analyzed. The 498 role, if any, of the background sea ice cover on the $\mathrm{SIC}_{\mathrm{DJF}}$, NS anomalies thus remains uncertain.

The main caveat of the model in Eq (1) is that the two predictor variables are not independent. $\triangle \mathrm{AMOC}_{\max , 60^{\circ} \mathrm{N}}$ and $\Delta \mathrm{SIC}_{\mathrm{JJA}, \mathrm{NS}}$ are correlated with an $\mathrm{r}^{2}$ of 0.34 , significant at the $95 \%$ level.

502 It is indeed very likely that the AMOC anomaly affects winter sea ice both directly, through 503 oceanic heat transport in winter, and indirectly, by influencing sea ice anomalies during 504 summer which, in turn, through ocean-sea ice-atmosphere feedbacks, can have a lasting effect 505 on the winter anomalies. Nevertheless, the AMOC may be affecting the annual sea ice 506 anomalies and, since sea ice seasonality is model-dependent, adding the summer sea ice as a 507 second predictor improves the results of the regression analysis. Such a regression could thus 508 allow to explain some of the spread that can be explained by local sea ice feedback and not 509 only the AMOC changes.

510 Summer sea ice cover anomalies are actually not entirely determined by the AMOC 511 differences. As shown in Figure 1, the Mid-Holocene experiences an important positive 512 summer radiative forcing in the high latitudes and the sensitivity of each model to this forcing 513 is very likely to have a strong effect on the summer sea ice anomalies. Since Mid-Holocene 514 forcing is seasonal and unevenly distributed over the globe, classical definitions of climate 515 sensitivity do not apply and could not be used to directly evaluate the model sensitivity effect 


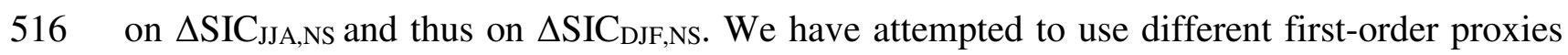

517 of this effect that would be less correlated with the AMOC change (such as summer SAT or 518 surface downward shortwave radiation anomalies over large domains in the Northern 519 Hemisphere) as a replacement for $\Delta \mathrm{SIC}_{\mathrm{JJA}, \mathrm{NS}}$ in the regression model above, but with 520 unsatisfactory results in terms of p-values and correlation coefficients.

\section{$521 \quad$ Link with future projections}

522 In order to estimate if simulated changes in the AMOC for the mid-Holocene are connected 523 with its behavior in climate projections, we have processed data from RCP85 projections. We 524 found 10 models from our PMIP3 pool that provide data for these projections. The scatterplot 525 of the anomalies in projections vs. anomalies for mid-Holocene is shown in Figure 14. A 526 significant correlation at the $95 \%$ level is found between the two, showing that models 527 simulating a stronger AMOC in the mid-Holocene also tend to simulate a stronger weakening 528 of the AMOC in RCP85 projections. This may indicate that models with a high AMOC 529 sensitivity to changes in mid-Holocene conditions also show a higher sensitivity of the 530 AMOC in future projections. Thus, constraining the changes in the AMOC for the mid531 Holocene may constitute a potential emergent constraint to reduce the very large uncertainty 532 of the AMOC response in future climates. Nevertheless, the relatively low correlation found 533 limits this interpretation. Also, quantitative estimates of AMOC variations over the Holoecne 534 are lacking, even though a few qualitative reconstructions exist (Kissel et al. 2013, Ayache et 535 al. 2018) and indicate that the AMOC may have been relatively intense during the mid536 Holocene. 


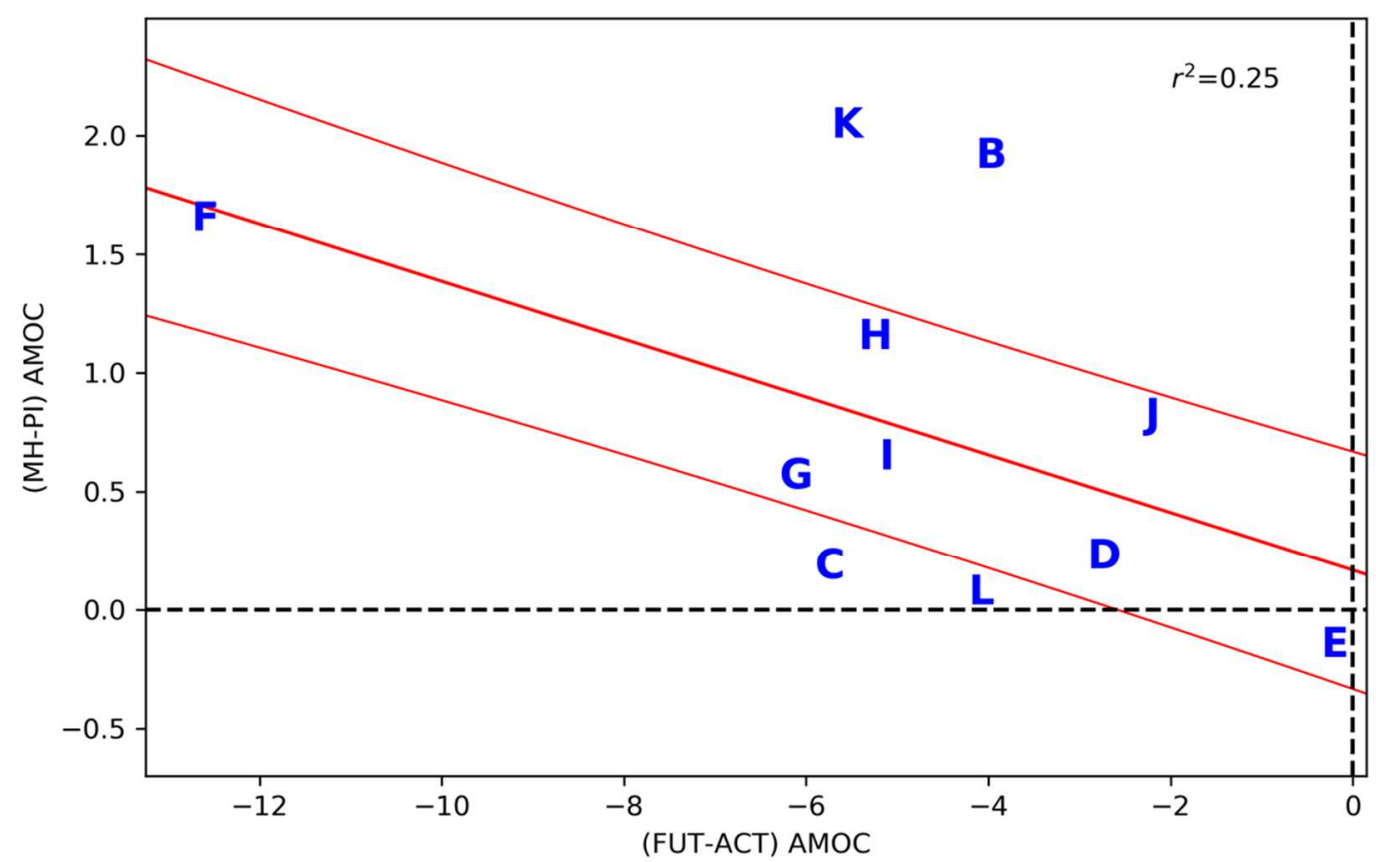

Figure 14. Relationship between mean $A M O C$ anomalies in mid-Holocene relative to preindustrial simulations and projections following an RCP85 scenario for the period 2081-2100 as compared to present-day period 20062015.

\section{Discussion and conclusions}

542 We have analyzed Mid-Holocene winter anomalies over the North Atlantic sector in 12

543 PMIP3 models with the purpose of comparing the simulated European winter temperature

544 anomalies with reconstructed data, and shedding light on their drivers.

545 Comparing the simulated winter near-surface air temperature anomalies with the recent 546 pollen-based reconstruction of Mauri et al. (2014) for the Mid-Holocene, we found some

547 qualitative agreement with the paleo-reconstruction for a few models, with pattern correlation

548 coefficients above 0.6 for 5 out of the 12 models, mostly reflecting a north-south temperature 549 anomaly gradient over Europe. All models underestimate the amplitude of the winter 550 anomalies, however, as well as the amplitude of this meridional gradient and the exact 551 anomaly pattern, compared to the Mauri et al. (2014) reconstruction. Nevertheless, the 
uncertainties of this reconstruction do allow for a weaker gradient as found in some of the models.

554 To understand the simulated response to mid-Holocene (MH) forcing, we have first analyzed 555 the simulated large-scale atmospheric circulation anomalies over the North Atlantic sector. 556 Our analysis has revealed a consistent climatological winter atmospheric response in mid557 Holocene consisting of two elements common to all models, though varying in spatial extent 558 and intensity. The first is a dynamically forced anti-cyclonic anomaly over the south-western 559 part of the North Atlantic, with a strong barotropic component. This structure is associated 560 with a local weakening of the jet stream and a more pronounced separation between the eddy561 driven and subtropical jet streams over the North Atlantic sector. The second element is a 562 positive sea-level pressure anomaly over northern Africa with a shallow baroclinic structure.

563 This SLP anomaly is a result of the colder atmospheric temperature in response to the strong 564 negative radiative forcing at low latitudes, the effects of which are amplified over continental 565 regions. In the same way, a shallow low-pressure anomaly is found in the north of the basin, 566 in thermal balance with positive temperature anomalies. For some models these SLP 567 anomalies could be interpreted as a $\mathrm{NAO}^{+}$signal, although the vertical structure of the NAO 568 is much more barotropic.

569 While some models exhibit a $\mathrm{NAO}^{+}$-like atmospheric circulation anomaly near the surface in 570 winter, the ensemble of 12 PMIP3 models does not support a link between this type of large571 scale atmospheric response and the $\mathrm{MH}$ temperature anomaly patterns over Europe. Instead, 572 the simulated $\mathrm{MH}$ European winter temperature anomaly patterns are, in most models, 573 determined by the radiatively forced cold anomalies at low latitudes and the more model574 dependent sea ice anomalies over the Nordic Seas, with the latter responsible for 575 approximately three times more inter-model variability than the former. 
The analyses carried out to understand the differences in these sea ice anomalies between the

577 models have revealed multiple footprints of the $\Delta$ SIC feedbacks onto other fields often dominating the climatological anomalies in the Nordic Seas region. We have shown here the signature of these feedbacks on the near-surface air temperature, but similar signatures have also been found (not shown) on other variables. A very tight collocation between strong

581 negative (positive) sea ice anomalies and negative (positive) near-surface horizontal wind 582 divergence anomalies was found in all models for which the latter could be calculated, likely explained by a response of the near-surface atmospheric circulation to the sea ice anomalies and to the associated air-sea flux anomalies. A local increase in cloud cover over negative $\Delta$ SIC regions (and vice-versa) has been found in most models, engendering marked local anomalies of the downward longwave and shortwave radiative fluxes at the surface (positive and negative respectively over regions of sea ice loss and vice-versa). A strong $\Delta \mathrm{SIC}$ feedback has also been found on the surface sensible heat flux ( $\mathrm{SH})$. In 3 out 12 models this corresponds to a simple positive response of $\mathrm{SH}$ to a positive $\Delta \mathrm{SIC}$ or vice-versa. In most models, however, the response is more complex, taking the form of a strong positive-negative 591 SH dipole over the $\Delta$ SIC region depending on the background sea ice cover, which shows a 592 subtle interplay of sea surface temperature and air temperature anomalies in these regions.

These ubiquitous sea ice feedback signatures confirm the importance of a correct sea ice 594 representation in the models for representing the regional climate over Europe. All but three models show a reduced winter sea ice cover in the Nordic Seas region in mid-Holocene compared to the pre-industrial climate. While not allowing for a quantitative model evaluation

597 of the sea-ice cover anomaly, a recent compilation of multi-proxy reconstructions of mid598 Holocene $\Delta$ SIC which expands on the data set used in Klein et al. (2014) (Seidenkrantz, 2015, 599 personal communication) qualitatively confirms this result. Nevertheless, the publication of 600 this compilation will be necessary to establish any strong observational constraints on this aspect. Based on this on-going work of compilation, we can suggest that an increase in Nordic 
602 Seas winter sea ice cover in the mid-Holocene, namely in FGOALS-g2, MIROC-ESM and

603 CCSM4, are not in line with the few available data for the MH climate in the North Atlantic

604 sector. It remains unclear if these mismatches are due to a poor response of the sea ice system

605 to insolation or are related to an ocean circulation response and its influence on the sea ice.

606 Sea ice feedback signatures dominating the climatological winter anomalies hinder the quest

607 for the causes of SIC anomalies in the model results. Nevertheless, we were able to highlight

608 a robust multi-model relationship between the MH winter SIC anomalies in the Nordic Seas

609 region and the anomalies in the Atlantic meridional overturning circulation, which points to

610 the AMOC as an important driver of the MH response of European winter temperatures.

611 The MH-PI differences in the atmospheric heat transport due to transient eddies form an 612 important potential source of information on the drivers of the SIC anomalies. However, these 613 differences could not be evaluated due to the lack of availability of the corresponding fields in 614 the PMIP3 data base. This type of drawback will be solved thanks to the inclusion of such 615 fields in the outputs from future model intercomparison exercises such as the upcoming 616 CMIP6 and PMIP4.

617 Another potential key player neglected here is the feedback from vegetation changes in the 618 high latitudes, which could also amplify the pattern found in the MH simulations (Wohlfahrt 619 et al. 2008), potentially bringing the model simulations closer to MH observations.

620 We also know that PMIP3 models systematically underestimate the monsoon anomalies in the 621 mid-Holocene (the "Green Sahara" event, Claussen \& Gayler 1997). It is plausible that this 622 event was linked to a northward shift of the Hadley Cell (Claussen and Gayler 1997), which 623 would therefore not be captured, or, at best, be severely underestimated by the models. We 624 conjecture that all models underestimate large-scale anomalies in the atmospheric circulation 625 that may have taken place (Gaetani et al. 2017) and may have affected temperature patterns 
over Europe during MH winters. Our study, however, highlights the potential relevance of

627 other effects, which deserve further study.

628 While previous, paleo-reconstruction-based studies, often attribute mid-Holocene winter 629 European temperature anomalies to a $\mathrm{NAO}^{+}-$like atmospheric circulation anomaly, our 630 analysis of PMIP3 models suggests the possibility of an additional or even alternative 631 explanation coming from a larger geographical context. In this new view, based on the most 632 skillful PMIP3 models, European winter temperature anomaly patterns are determined, to the 633 south, by strong low-latitude temperature responses to the seasonal negative radiative forcing 634 and to the north by feedbacks of the negative sea ice anomalies over the Nordic Seas on the 635 atmosphere. Model simulations also suggest that a major driving force for these sea ice 636 anomalies is an intensification of the Atlantic meridional overturning circulation in the mid637 Holocene compared to the modern period, as indirectly suspected in Masson et al. (1999). 638 This is in agreement with reconstructions based on sortable silt in the North Atlantic, a proxy 639 of deep water circulation, which indicate a stronger deep current during the MH (Kissel et al. 640 2013). The amplitude of the north-south gradient over Europe is weaker in the models than in 641 the reconstruction. We can suggest that this is related to a general bias of climate models in 642 representing the strong air-sea interaction as recently highlighted by the so-called signal to 643 noise paradox by Scaife et al. (2018).

644 The summertime temperature reconstruction from Mauri et al. (2014) does not show any 645 agreement with model simulations and leads to very different patterns than the model 646 simulations (not shown, $c f$. Mauri et al. 2014). This weakens the hypothesis expressed here. 647 The analysis of the differences between models and reconstruction data is out of the scope of 648 the present paper and deserves a dedicated study. Nevertheless, we can highlight here that 649 changes in the AMOC mainly affect European temperature in winter (e.g. Figure 4 from 
650 Jackson et al. 2015), and may have a far weaker signature on summer temperatures, where 651 other processes might be dominant.

652 The cause for the differences in the AMOC has not been analyzed in the present paper, as it 653 will also necessitate a dedicated study. As noticed before, this could be related to a decrease 654 in sea ice transport through the Fram Strait due to a lower sea ice production when insolation 655 is larger in summer (Born et al. 2010). This shows that the AMOC is not only influencing the 656 sea ice, but could also be modified by it, implying a two-way feedback also potentially at play 657 in the Nordic Seas. Another interesting factor could be related to the influence of the 658 atmospheric circulation on the AMOC. For instance, variability of the AMOC over the last 60 659 years has often been related to NAO variations (Delworth et al. 2016; Swingedouw et al. 660 2015b). The mechanism is related to a cooling of the surface Labrador Sea during $\mathrm{NAO}^{+}$ 661 phases, which increases the Labrador deep water formation and, a few years later, the AMOC 662 (Eden and Willebrand 2001). Thus, if the atmospheric circulation during the $\mathrm{MH}$ changed 663 towards a $\mathrm{NAO}^{+}$-like configuration, then it likely amplified the AMOC, as highlighted in Shi 664 and Lohman (2016) for the ECHAM-FESOM-MPIOM climate model. In the MH PMIP3 ensemble, however, the NAO changes are not the main driver, since our indices of NAO and AMOC changes are not significantly correlated (not shown).

667 If this interpretation is correct, then the MH European winter temperatures may be a test-bed 668 to estimate possible changes in sea ice and in the AMOC in the near future, with the role of 669 the NAO to be further investigated in larger multi-model ensembles. Since, as we find here, 670 the inter-model differences in $\mathrm{MH}$ temperature anomalies are mainly explained by AMOC 671 changes, we conclude that the $\mathrm{MH}$ is indeed an interesting case study to evaluate the 672 sensitivity of the simulated AMOC to changes in radiative forcing. Indeed, changes in the 673 simulated AMOC for RCP85 projections generally exhibit strong weakening in models that 674 show large strengthening for mid-Holocene. The linear relationship is nonetheless not very 
675 strong and the interpretation is limited by the low number of models analyzed here. The proof

676 of concept presented here will thus benefit from a higher number of models, which will be 677 hopefully reached within CMIP6.

678 Furthermore, to produce a correct assessment of models, we need to have a finer, quantitative 679 AMOC reconstruction for this period. The use of a methodology combining climate models 680 and available observational datasets, as employed for the deglaciation by Ritz et al. (2013) for 681 instance, is an interesting approach to be developed. This may help to better decipher the 682 sensitivity of the AMOC to different forcings, which could then provide new leads to reduce 683 the very large uncertainty (Weaver et al. 2012) concerning the future of the AMOC. For this 684 purpose, the use of more models available with paleo-configuration will be a key prerequisite, since the analysis led here clearly suffers from the low number of models available within 686 CMIP5.

\section{Acknowledgements}

688 We wish to thank Marrit-Solveig Seidenkrantz, Hugues Goosse and Frédéric Hourdin for fruitful discussions that have benefitted our study. This project would not have been possible

690 without the availability of PMIP3 data in a centralized, consistent format, for which we are 691 deeply thankful to the climate modeling centers listed in Table 1, to the groups behind the 692 ESGF portal, and in particular to Guillaume Levavasseur and Jean-Yves Peterschmitt, as well 693 as the FileFinderAR5 developed by Patrick Brockmann. To analyze the PMIP3 data, this 694 study benefited from the IPSL Prodiguer-Ciclad facility supported by CNRS, UPMC, Labex 695 L-IPSL which is funded by the ANR (Grant \#ANR-10-LABX-0018) and by the European 696 FP7 IS-ENES2 project (Grant \#312979). AGB was supported by the Swedish Research 697 Council Grant No. C0629701 (MILEX). The research leading to this study also received 698 funding from the French National Research Agency HAMOC project (Grant ANR-13-BS06- 
7002020 research and innovation programme, grant number: 727852) and the EUCP project

701 (European Union's Horizon 2020 research and innovation programme under grant agreement 702 no 776613).

\section{References}

704

Årthun, M. et al. (2017) Skillful prediction of northern climate provided by the ocean. Nat. Commun. 8, 15875 doi: 10.1038/ncomms15875.

Ayache M. Swingedouw D., Mary Y., Eynaud F., Colin C. (2018) AMOC variability over the Holocene: A new reconstruction based on multiple proxy-based SST records. Global and Planetary Changes 170, pp. 172-189.

Bakker, P., and Coauthors, 2016: Fate of the Atlantic Meridional Overturning Circulation Strong decline under continued warming and Greenland melting. Geophys. Res. Lett., 19, doi:10.1002/2016GL070457. http://onlinelibrary.wiley.com/doi/10.1002/2016GL070457/abstract.

Bao, Q., and Coauthors, 2013: The Flexible Global Ocean-Atmosphere-Land system model, Spectral Version 2: FGOALS-s2. Adv. Atmos. Sci., 30, 561-576, doi:10.1007/s00376012-2113-9.

Berger, M., J. Brandefelt, and J. Nilsson, 2013: The sensitivity of the Arctic sea ice to orbitally induced insolation changes: A study of the mid-holocene paleoclimate modeling intercomparison project 2 and 3 simulations. Clim. Past, 9, 969-982, doi:10.5194/cp-9-969-2013.

Boning, C. W., F. O. Bryan, W. R. Holland, and R. Doscher, 1995: Deep water formation and meridional overturning in a high-resolution model ofthe North Atlantic. J. Phys. Oceanogr., 26, 1142-1164.

Born, A., K. H. Nisancioglu, and P. Braconnot, 2010: Sea ice induced changes in ocean 
circulation during the Eemian. Clim. Dyn., 35, 1361-1371, doi:10.1007/s00382-0090709-2.

726

727

728

729

730

731

732

733

734

735

736

737

738

739

740

741

742

743

744

745

746

747

Born, J. Mignot and T.F. Stocker (2015) Multiple Equilibria as a Possible Mechanism for Decadal Variability in the North Atlantic Ocean. Journal of Climate 28, 8907-8922

Braconnot, P., S. P. Harrison, M. Kageyama, P. J. Bartlein, V. Masson-Delmotte, A. AbeOuchi, B. Otto-Bliesner, and Y. Zhao, 2012: Evaluation of climate models using palaeoclimatic data. Nat. Clim. Chang., 2, 417-424, doi:10.1038/nclimate1456. http://dx.doi.org/10.1038/nclimate1456.

Brewer, S., Guiot, J., and Torre, F.: Mid-Holocene climate change in Europe: a data-model comparison, Clim. Past, 3, 499-512, https://doi.org/10.5194/cp-3-499-2007, 2007.

Cattiaux, J., and C. Cassou, 2013: Opposite CMIP3/CMIP5 trends in the wintertime Northern Annular Mode explained by combined local sea ice and remote tropical influences. Geophys. Res. Lett., 40, 3682-3687, doi:10.1002/grl.50643.

Chabaud, L., M. F. Sanchez Goni, S. Desprat, and L. Rossignol, 2014: Land-sea climatic variability in the eastern North Atlantic subtropical region over the last 14,200 years: Atmospheric and oceanic processes at different timescales. The Holocene, 24, 787-797, doi:10.1177/0959683614530439.

Claussen, M., and V. Gayler, 1997: The Greening of the Sahara during the Mid-Holocene: Results of an Interactive Atmosphere-Biome Model. Glob. Ecol. Biogeogr. Lett., 6, 369377.

Collins, W. J., N. Bellouin, N. Gedney, P. Halloran, T. Hinton, J. Hughes, and C. D. Jones, 2011: Model Development Development and evaluation of an Earth-System model HadGEM2. 1051-1075, doi:10.5194/gmd-4-1051-2011.

Conil, S., and L. Z.-X. Li, 2005: Linearity of the Atmospheric Response to \textsc $\{\mathrm{N}\}$ orth 
Itextsc $\{$ A $\}$ tlantic SST and Sea Ice Anomalies. J. $\backslash$ Clim., 18, 1986-2003. http://dx.doi.org/10.1175/JCLI3388.1.

Davis, B. A. S., and S. Brewer, 2009: Orbital forcing and role of the latitudinal insolation/temperature gradient. Clim. Dyn., 32, 143-165, doi:10.1007/s00382-0080480-9.

Delworth, T. L., F. Zeng, G. A. Vecchi, X. Yang, L. Zhang, and R. Zhang, 2016: The North Atlantic Oscillation as a driver of rapid climate change in the Northern Hemisphere. Nat. Geosci., 9, 509-512, doi:10.1038/ngeo2738.

Deser, C., R. Knutti, S. Solomon, and A. S. Phillips, 2012: Communication of the role of natural variability in future North American climate. Nat. Clim. Chang., 2, 775-779, doi:10.1038/nclimate1562. http://dx.doi.org/10.1038/nclimate1562.

Dufresne, J. L., and Coauthors, 2013: Climate change projections using the IPSL-CM5 Earth System Model: From CMIP3 to CMIP5. 2123-2165 pp.

Eden, C., and J. Willebrand, 2001: Mechanisms of interannual to decadal variability of the North Atlantic circulation. J. Clim., 14, 2266-2280, doi:10.1175/15200442(2001)014<2266:MOITDV>2.0.CO;2.

Escudier, R., J. Mignot, and D. Swingedouw, 2013: A 20-year coupled ocean-sea iceatmosphere variability mode in the North Atlantic in an AOGCM. Clim. Dyn., 40, 619636.

Fischer, N., and J. H. Jungclaus, 2011: Evolution of the seasonal temperature cycle in a transient Holocene simulation: Orbital forcing and sea-ice. Clim. Past, 7, 1139-1148, doi:10.5194/cp-7-1139-2011.

Fischer et al. (2018) Palaeoclimate constraints on the impact of $2{ }^{\circ} \mathrm{C}$ anthropogenic warming and beyond. Nat. Geosc. 1, 474-485. 
772 Gaetani M., Messori G., Zhang Q., Flamant C., Pausata F. S. R. (2017) Understanding the mechanisms behind the northward extension of the West African Monsoon during the Mid-Holocene. Journal of Climate, American Meteorological Society, 2017, 30 (19), pp.7621-7642.

Gent, P. R., and Coauthors, 2011: The community climate system model version 4. J. Clim., 24, 4973-4991, doi:10.1175/2011JCLI4083.1.

Gladstone, R. M., and Coauthors, 2005: Mid-Holocene NAO: A PMIP2 model intercomparison. Geophys. Res. Lett., 32, 1-4, doi:10.1029/2005GL023596.

Goosse, H., F. Selten, R. Haarsma, and J. Opsteegh, 2002: A mechanism of decadal variability of the sea-ice volume in the Northern Hemisphere. Clim. Dyn., 19, 61-83, doi:10.1007/s00382-001-0209-5.

Guyard, H., E. Chapron, G. St-Onge, and J. Labrie, 2013: Late-Holocene NAO and oceanic forcing on high-altitude proglacial sedimentation (Lake Bramant, Western French Alps). The Holocene, 23, 1163-1172, doi:10.1177/0959683613483616. http://hol.sagepub.com/content/23/8/1163.abstract.

Haarsma, R. J., F. M. Selten and S. S. Drijfhout (2015) Decelerating Atlantic meridional overturning circulation main cause of future west European summer atmospheric circulation changes. Environmental Research Letters, 10 (9), doi:10.1088/17489326/10/9/094007.

Harrison, S. P., P. J. Bartlein, K. Izumi, G. Li, J. Annan, J. Hargreaves, P. Braconnot, and M. Kageyama, 2015: Evaluation of CMIP5 palaeo-simulations to improve climate projections. Nat. Clim. Chang., 5, 735-743, doi:10.1038/nclimate2649. http://www.nature.com/doifinder/10.1038/nclimate2649.

Hawkins, E., and R. Sutton, 2009: The potential to narrow uncertainty in regional climate predictions. Bull. Am. Meteorol. Soc., 90, 1095-1107, doi:10.1175/2009BAMS2607.1. 
Huck, T., A. De Colin Verdière, P. Estrade, and R. Schopp, 2008: Low-frequency variations of the large-scale ocean circulation and heat transport in the North Atlantic from 19551998 in situ temperature and salinity data. Geophys. Res. Lett., 35, 1-5, doi:10.1029/2008GL035635.

Hurrell, J. W., 1995: Decadal Trends in the North Atlantic Oscillation : Regional Temperatures and Precipitation. Science Vol. 269, No. 5224, pp. 676-679.

Hurrell, J. W., and C. Deser, 2010: North Atlantic climate variability: The role of the North Atlantic Oscillation. J. Mar. Syst., 79, 231-244, doi:10.1016/j.jmarsys.2009.11.002.

IPCC Working Group 1, I., and Coauthors, 2013: IPCC, 2013: Climate Change 2013: The Physical Science Basis. Contribution of Working Group I to the Fifth Assessment Report of the Intergovernmental Panel on Climate Change. IPCC, AR5, 1535.

Jackson, L. C. et al. (2015) Global and European climate impacts of a slowdown of the AMOC in a high resolution GCM. Climate Dynamics, 45 (11-12), 3299-3316, doi:10.1007/s00382-015-2540-2.

Joshi et al. (2008) Mechanisms for the land/sea warming contrast exhibited by simulations of climate change. Climate Dynamics 30: 455. https://doi.org/10.1007/s00382-007-0306-1

Jungclaus, J. H., and Coauthors, 2013: Characteristics of the ocean simulations in the Max Planck Institute Ocean Model ( MPIOM ) the ocean component of the MPI-Earth system model. 5, 422-446, doi:10.1002/jame.20023.

Kissel, C., A. Van Toer, C. Laj, E. Cortijo, and E. Michel, 2013: Variations in the strength of the North Atlantic bottom water during Holocene. Earth Planet. Sci. Lett., 369-370, 248-259, doi:10.1016/j.epsl.2013.03.042. http://dx.doi.org/10.1016/j.eps1.2013.03.042.

Klein, F., H. Goosse, A. Mairesse, A. De Vernal, and P. L. Pasteur, 2014: Model - data comparison and data assimilation of mid-Holocene Arctic sea ice concentration. 11451163, doi:10.5194/cp-10-1145-2014. 
Li, L., and Coauthors, 2013: The flexible global ocean-atmosphere-land system model, Gridpoint Version 2: FGOALS-g2. Adv. Atmos. Sci., 30, 543-560, doi:10.1007/s00376-0122140-6.

Masson, V., R. Cheddadi, P. Braconnot, S. Joussaume, and D. Texier, 1999: Mid-Holocene climate in Europe: What can we infer from PMIP model-data comparisons? Clim. Dyn., 15, 163-182, doi:10.1007/s003820050275.

Massonnet F., T. Fichefet, H. Goosse, C. M. Bitz, G. Philippon-Berthier, M. M. Holland, P. Y. Barriat (2012) Constraining projections of summer Arctic sea ice. The Cryosphere 6, 1383-1394.

Mauri, A., B. A. S. Davis, P. M. Collins, and J. O. Kaplan, 2014: The influence of atmospheric circulation on the mid-Holocene climate of Europe: A data-model comparison. Clim. Past, 10, 1925-1938, doi:10.5194/cp-10-1925-2014.

McCarthy, G. D. et al., 2015: Measuring the Atlantic Meridional Overturning Circulation at 26 degrees N. Progress in Oceanography, 130, 91-111, doi:10.1016/j.pocean.2014.10.006.

Otto, J., T. Raddatz, and M. Claussen, 2009: Climate variability-induced uncertainty in midHolocene atmosphere-ocean-vegetation feedbacks. Geophys. Res. Lett., 36, 1-5, doi:10.1029/2009GL041457.

Ritz, S. P., T. F. Stocker, J. O. Grimalt, L. Menviel, and A. Timmermann, 2013: Estimated strength of the Atlantic overturning circulation during the last deglaciation. Nat. Geosci., 6, 208-212, doi:10.1038/ngeo1723. http://www.nature.com/doifinder/10.1038/ngeo1723.

Rotstayn, L. D., S. J. Jeffrey, M. A. Collier, S. M. Dravitzki, A. C. Hirst, J. I. Syktus, and K. K. Wong, 2012: and Physics Aerosol- and greenhouse gas-induced changes in summer rainfall and circulation in the Australasian region : a study using single-forcing climate simulations. 6377-6404, doi:10.5194/acp-12-6377-2012. 
Saint-Lu, M., P. Braconnot, J. Leloup, and O. Marti, 2016: The role of El Ni??o in the global energy redistribution: a case study in the mid-Holocene. Clim. Dyn., 1-18, doi:10.1007/s00382-016-3266-5.

Scaife A., Smith, D. (2018) A signal-to-noise paradox in climate science. Climate and Atmospheric Science 1:28; doi:10.1038/s41612-018-0038-4

Schmidt, G. A., and Coauthors, 2006: Present-Day Atmospheric Simulations Using GISS ModelE: Comparison to In Situ, Satellite, and Reanalysis Data. J. Clim., 19, 153-192, doi:10.1175/JCLI3612.1. http://journals.ametsoc.org/doi/abs/10.1175/JCLI3612.1.

Schmidt, G. A., and Coauthors, 2014: Using palaeo-climate comparisons to constrain future projections in CMIP5. Clim. Past, 10, 221-250, doi:10.5194/cp-10-221-2014.

Shi, X., and G. Lohmann (2016), Simulated response of the mid- Holocene Atlantic meridional overturning circulation in ECHAM6-FESOM/MPIOM, J. Geophys. Res. Oceans, 121, 6444-6469, doi:10.1002/ 2015JC011584.

Swingedouw, D., P. Braconnot, and O. Marti, 2006: Sensitivity of the Atlantic Meridional Overturning Circulation to the melting from northern glaciers in climate change experiments. Geophys. Res. Lett., 33.

— J. Mignot, P. Braconnot, E. Mosquet, M. Kageyama, and R. Alkama, 2009: Impact of freshwater release in the north atlantic under different climate conditions in an OAGCM. J. Clim., 22, 6377-6403, doi:10.1175/2009JCLI3028.1.

Swingedouw, D., C. B. Rodehacke, S. M. Olsen, M. Menary, Y. Gao, U. Mikolajewicz, and J. Mignot, 2015a: On the reduced sensitivity of the Atlantic overturning to Greenland ice sheet melting in projections: a multi-model assessment. Clim. Dyn., 44, 3261-3279, doi:10.1007/s00382-014-2270-x. http://dx.doi.org/10.1007/s00382-014-2270-x. 

variability controlled by timing of volcanic eruptions. Nat. Commun., 6, pages: 6545 .

872 Voldoire, A., and Coauthors, 2013: The CNRM-CM5.1 global climate model: Description 873 and basic evaluation. Clim. Dyn., 40, 2091-2121, doi:10.1007/s00382-011-1259-y.

874 Watanabe, M., M. Chikira, Y. Imada, and M. Kimoto, 2011: Convective control of ENSO 875 simulated in MIROC. J. Clim., 24, 543-562, doi:10.1175/2010JCLI3878.1.

Weaver, A. J., and Coauthors, 2012: Stability of the Atlantic meridional overturning circulation: A model intercomparison. Geophys. Res. Lett., 39, 1-7, doi:10.1029/2012GL053763.

Wohlfahrt, J., S. P. Harrison, P. Braconnot, C. D. Hewitt, A. Kitoh, U. Mikolajewicz, B. L. Otto-Bliesner, and S. L. Weber, 2008: Evaluation of coupled ocean-atmosphere simulations of the mid-Holocene using palaeovegetation data from the northern hemisphere extratropics. Clim. Dyn., 31, 871-890, doi:10.1007/s00382-008-0415-5.

883 Xin, X., L. Zhang, J. Zhang, T. Wu, and Y. Fang, 2013: Climate Change Projections over 884 East Asia with BCC _ CSM1 . 1 Climate Model under RCP Scenarios. 91, 413-429, doi:10.2151/jmsj.2013-401.

Yukimoto, S., Y. Adachi, M. Hosaka, and T. Sakami, 2012: A New Global Climate Model of the Meteorological Research Institute : MRI-CGCM3 - Model Description and Basic Performance —. 90, doi:10.2151/jmsj.2012-A02. 